\title{
The genetics of colony form and function in Caribbean Acropora corals
}

\author{
Elizabeth M Hemond,' Stefan T Kaluziak and Steven V Vollmer
}

\begin{abstract}
Background: Colonial reef-building corals have evolved a broad spectrum of colony morphologies based on coordinated asexual reproduction of polyps on a secreted calcium carbonate skeleton. Though cnidarians have been shown to possess and use similar developmental genes to bilaterians during larval development and polyp formation, little is known about genetic regulation of colony morphology in hard corals. We used RNA-seq to evaluate transcriptomic differences between functionally distinct regions of the coral (apical branch tips and branch bases) in two species of Caribbean Acropora, the staghorn coral, A. cervicornis, and the elkhorn coral, A. palmata.

Results: Transcriptome-wide gene profiles differed significantly between different parts of the coral colony as well as between species. Genes showing differential expression between branch tips and bases were involved in developmental signaling pathways, such as Wnt, Notch, and BMP, as well as pH regulation, ion transport, extracellular matrix production and other processes. Differences both within colonies and between species identify a relatively small number of genes that may contribute to the distinct "staghorn" versus "elkhorn" morphologies of these two sister species.

Conclusions: The large number of differentially expressed genes supports a strong division of labor between coral branch tips and branch bases. Genes involved in growth of mature Acropora colonies include the classical signaling pathways associated with development of cnidarian larvae and polyps as well as morphological determination in higher metazoans.
\end{abstract}

Keywords: Coral Reefs, Acropora, Cnidaria, Gene expression, RNA-seq

\section{Background}

Colonial modular organisms, such as corals, bryozoans, and tunicates, are formed from groups of asexually produced, genetically identical modules ('polyps' or 'zooids') that are interconnected to produce an integrated superorganism [1]. Modules are connected by living tissue, which allows intra-colony communication, resource sharing [2], and in some cases a coordinated division of labor (DOL) permits specific modules to specialize in feeding, reproduction or defense [3,4]. The coordination of growth among modules can create diverse colony morphologies, such as those in tropical reef-building corals ranging from simple hemispherical and plating colonies to complex branching colonies.

Scleractinian (hard) coral colonies have a simple body plan of polyps and connecting tissue overlaid on top of a

*Correspondence: lizhemond@gmail.com

Northeastern University, Marine Science Center, Nahant, MA, USA secreted aragonite (calcium carbonate) skeleton. The coral animal is comprised of anemone-like polyps with a gastrovascular cavity formed by two cell layers (ectoderm and endoderm) separated by a layer of mesogloea. The polyps are interconnected by a layer of tissue (coenosarc) overlaying the skeleton, but may also share coelenteric canals within the skeleton [5]. Colony integration and interpolyp communication is evident in the elaborate colony morphologies formed by corals, which often serve as key identifying characteristics of species [6]. However, within species some morphological variation may also occur due to environmentally-induced phenotypic plasticity $[7,8]$ or genetic polymorphism.

The genetic mechanisms underlying colony growth are poorly understood, but cnidarian genomes are known to contain many of the key genes expressed during coordinated development of bilaterians, such as Hox/ParaHox [9], Hedgehog [10], Wnt [11-13], TGFß/BMP [14,15], Notch $[16,17]$ and other developmental signaling pathways 
[18-22]. Some of these developmental genes, including Hox/ParaHox and Wnt genes, have been shown to function in axial patterning of the solitary freshwater hydrozoan Hydra [23-26], the colonial marine hydrozoan Hydractinia echinata [27,28], the solitary marine anthozoan Nematostella vectensis [12,29], as well as in the early developmental stages of scleractinian corals [30,31]. A ParaHox gene, cnox-2, has also been associated with DOL among zooids in hydrozoans [32,33], likely relating to the development or exclusion of oral structures. Additionally, characteristic gene expression differences have been observed between swimming (nectophore) and feeding (gastrozooid) zooids in siphonophores (Hydrozoa) [4]. These findings suggest that other colonial cnidarians, including some corals, may show polyp-specific transcription. The genetics of coral development has been examined through post-larval settlement $[34,35]$, yet little is known about the basis of either colony coordination or DOL in mature colonies.

Branching Acropora corals are a good system for studying genetic regulation of growth form and colony coordination in anthozoans, because corals in this genus (with the exception of the subgenus Isopora) exhibit dimorphic polyp types. Acropora corals have axial polyps with six tentacles located at the apical tip of their branches and radial polyps with twelve tentacles located along the sides of the branches. Axial polyps are typically the site of rapid growth and have lighter coloration due to a lower concentration of symbiont algae (i.e. Symbiodinium or zooxanthellae) [2,36-40]. In contrast, radial polyps are generally smaller and have darker pigmentation corresponding to higher symbiont densities. Actively growing branch tips in Acropora corals are usually sterile, and gamete production occurs only in mature radial polyps [36,41-43]. Acropora have diversified into the most specious genus of scleractinian corals with over 120 described species and growth forms ranging from arborescent, such as A. cervicornis, to more tabulate forms, such as A. palmata. The success of these growth forms has enabled Acropora corals to colonize a wide range of habitats and become dominant reefbuilding corals both in the Indo-Pacific and the Caribbean. However, the genetic basis of this DOL within the colony remains unknown. One microarray study examined differential gene expression within $A$. millepora and found few differences between bases and tips of the branches. Differences were limited to lysosome lipase activity and fluorescence [44], which do not explain the large functional differences within the colony.

Despite the extensive species diversity globally, the Caribbean has only two Acropora species (Figure 1), the staghorn coral, $A$. cervicornis, and the elkhorn coral, $A$. palmata, which are known to hybridize, generating an intermediate morphology hybrid called A. prolifera [45]. These two sister species, which have distinct morphologies allowing them to occupy different habitats, are thought to have diverged over three million years ago, when $A$. palmata first appears in the fossil record [46]. A. palmata, which has robust branches with fused axial polyps, inhabits the shallow, high-energy reef crest, whereas $A$. cervicornis, which has thin branches generally dominated by a single axial polyp, tends to inhabit the fore-reef and back-reef habitats.

High-throughput sequencing facilitates the characterization and quantification of whole transcriptomes in non-model organisms and is a powerful new tool for studying species of conservation concern, such as Acropora corals. This technology is already being used to

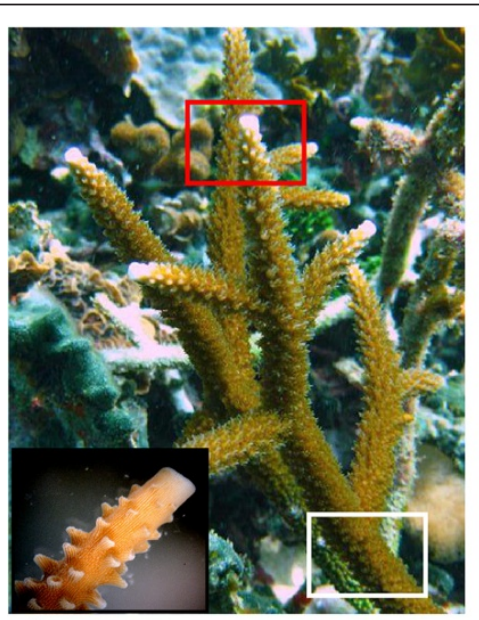

A

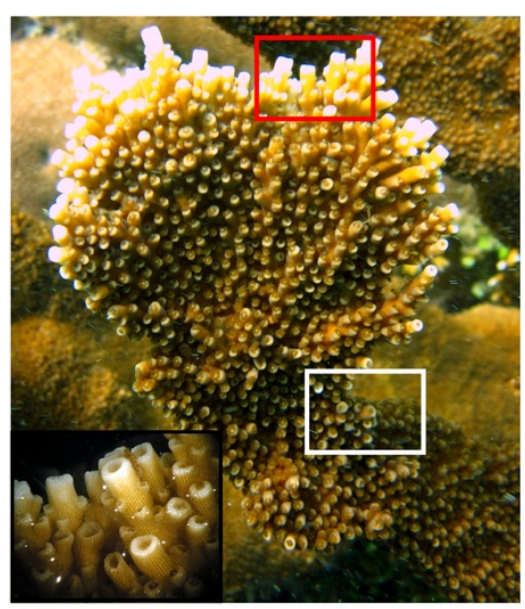

B

Figure 1 Branch morphology of $A$. cervicornis (A) and A. palmata (B), with insets showing branch tips. Regions of sampling for branch tips (red boxes) and bases (white boxes). 
study issues such as coral response to climate change [47-49] and disease [50], and is the best currently available method to comprehensively study total transcriptomic variation. In this study, we used Illumina RNA sequencing (RNA-seq) to examine within-colony gene expression differences in the two Caribbean Acropora species, comparing actively growing apical branch tips to less actively growing branch bases. We examined overall gene expression differences within the coral colonies and between species, and we evaluated the differentially expressed (DE) genes for patterns relating to growth, polyp development, and deposition of a mineralized skeleton. Here we describe and focus on (1) genes that are DE between branch bases and branch tips for both species (i.e. DE by colony position), which indicate processes that contribute to or arise from DOL within the colony, and (2) genes that are DE by both colony position and species, which indicate processes that may be involved in facilitating morphological differences between species.

\section{Results and discussion}

Transcriptome-wide RNA-seq profiles

The RNA-seq libraries contained an average of 4.7 million reads, with 3.6 million mapped reads (see Additional file 1). The combined A. cervicornis and $A$. palmata coral-only dataset included 47,748 transcripts, of which 23,554 transcripts were expressed at least 100 normalized counts, and 22,320 transcripts remained after removing those with group $\mathrm{SD}>$ mean. Of the 22,320 transcripts in the coral dataset, nearly 15,000 were annotated with known or predicted proteins at an e-value $<10^{-5}$ in the UniProt database (see Additional file 2).

Non-metric multidimensional scaling (nMDS) analyses of the gene expression profiles show that the samples form distinct groups by species (A. cervicornis and A. palmata) and by colony position (tip and base) (Figure 2). PERMANOVA analyses indicate that polyps sampled from different locations along the colony branch have highly different gene expression profiles (d.f. $=1$, Pseudo- $\mathrm{F}=$ 4.4169, $\mathrm{P}=0.001$ ), as do polyps sampled from the two species (d.f. $=1$, Pseudo- $\mathrm{F}=5.8765, \mathrm{P}=0.001$ ). However, there was no significant interaction between these factors for the transcription profiles as a whole (d.f. $=1$, Pseudo-F $=0.9161, \mathrm{P}=0.480$ ).

\section{Differentially expressed genes}

A two-factor, negative binomial generalized linear model (GLM) was used to identify differentially expressed (DE) genes that differed significantly due to colony position and species or that had an interaction effect between factors (Figure 3; for annotated DE genes see Additional file 2). Out of the 2288 transcripts DE by species, $50 \%$ were up-regulated in A. cervicornis and $50 \%$ were upregulated in A. palmata (Figure 4A). Out of the 2215 transcripts DE by colony position, $60 \%$ were up-regulated in branch tips and $40 \%$ were up-regulated in bases (Figure 4B). To elucidate the differences associated with DOL between branch base and branch tips consistent for both species, we focus on the 679 annotated transcripts DE with $>2$-fold change in gene expression as a function of colony position only. To understand the genetic underpinnings of differences in growth morphology between A. cervicornis and A. palmata, we focus on transcripts that were DE for both colony position and species with $>2$-fold change in gene expression or were significant for the interaction between factors. A total of 315 transcripts were DE for both factors and nine transcripts showed a significant interaction between factors. Of these, 69 transcripts were annotated with known or predicted proteins (Figure 5).

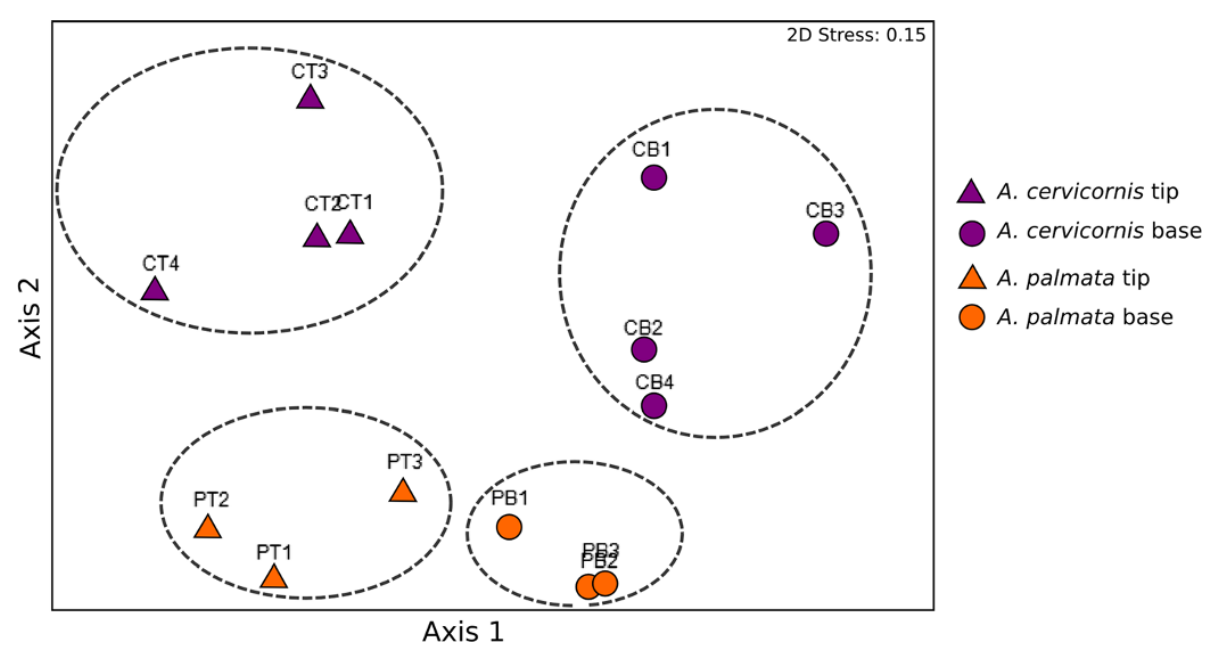

Figure 2 nMDS for all samples and transcripts expressed at $>100$ total normalized counts $(n=23,554)$. Dashed lines delineate groups of samples. 
Figure 3 Number of DE genes for factors (colony position and species) and their interaction. Venn diagrams include results for all coral transcripts (A), annotated transcripts (B), and annotated transcripts with greater than 2 -fold difference between treatments (C).

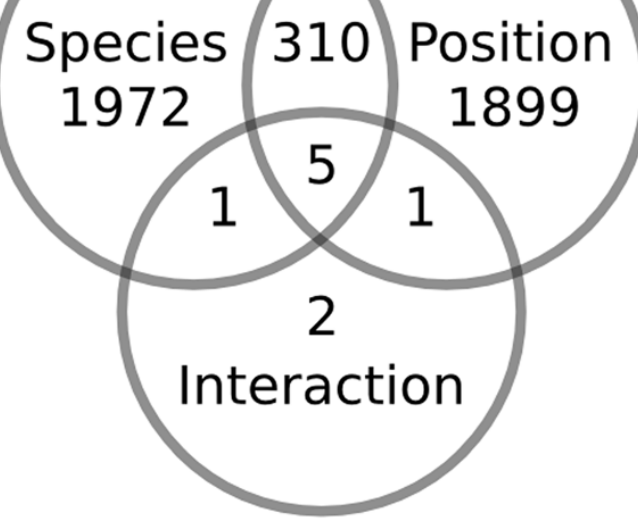

B

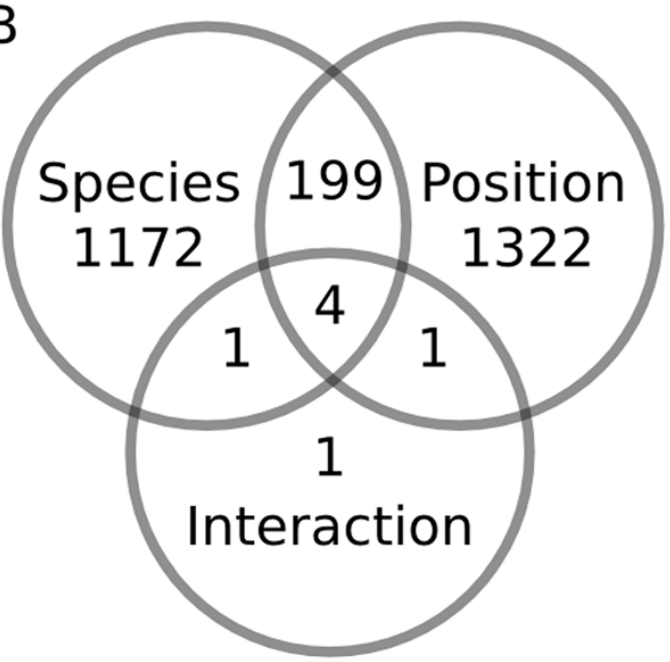

C

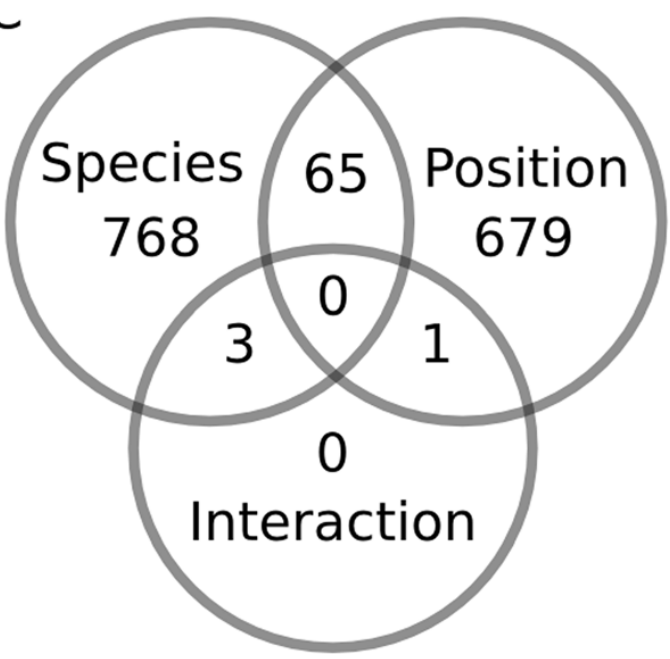

Biological function of $D E$ genes

Within an Acropora colony, branch tips are the site of rapid growth, a process including both asexual reproduction of polyps and skeleton deposition, each regulated by a number of biological functions. The basal/radial
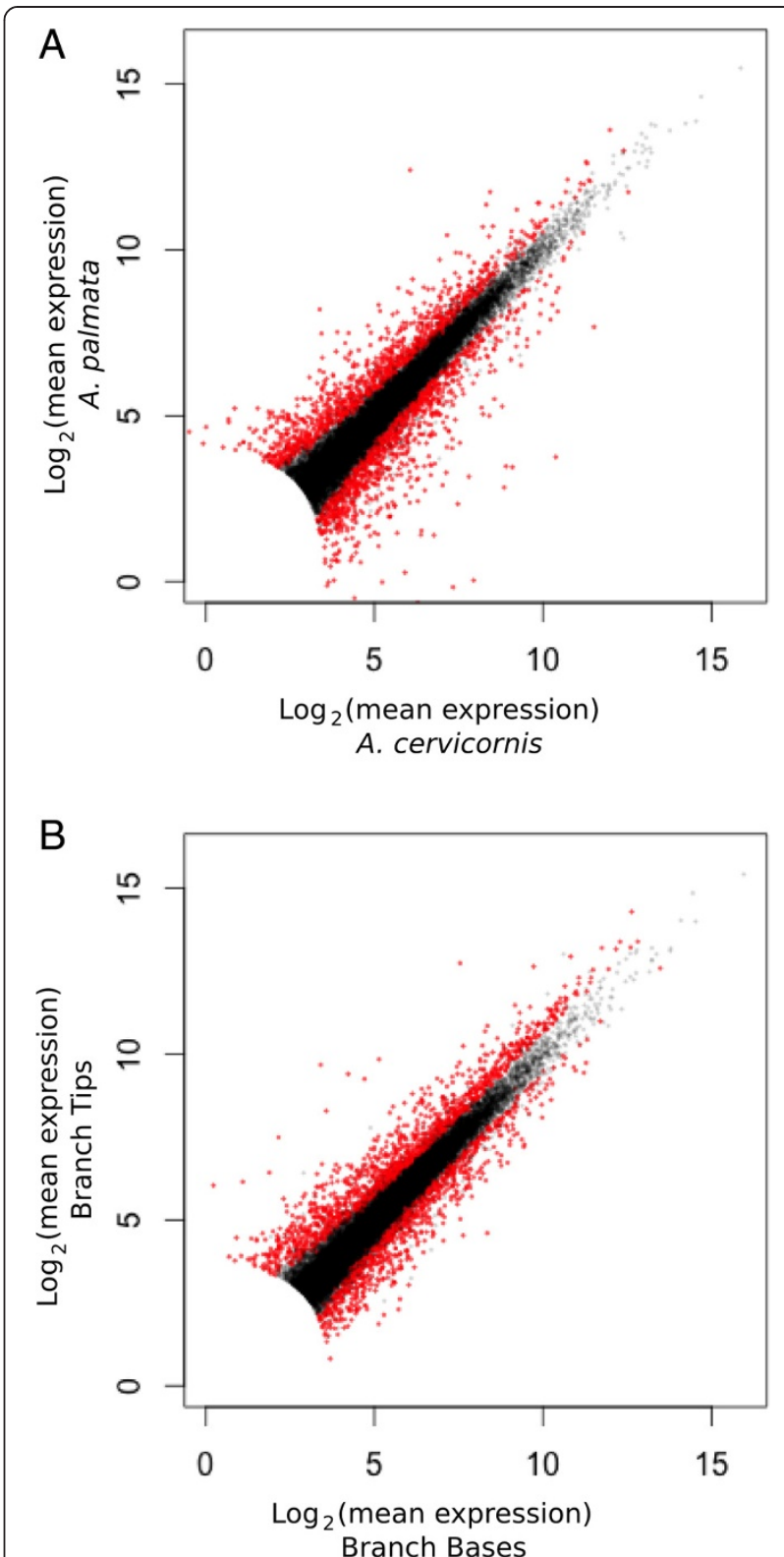

Figure 4 Scatter plots of gene expression for all genes in the dataset ( $n=22,320)$. Species (A) and colony position (B) comparisons with DE transcripts in red $\left(P_{\text {adj }}<0.05\right)$. Filtering of transcripts expressed at $<100$ total normalized counts results in the loss of points around the origin. 

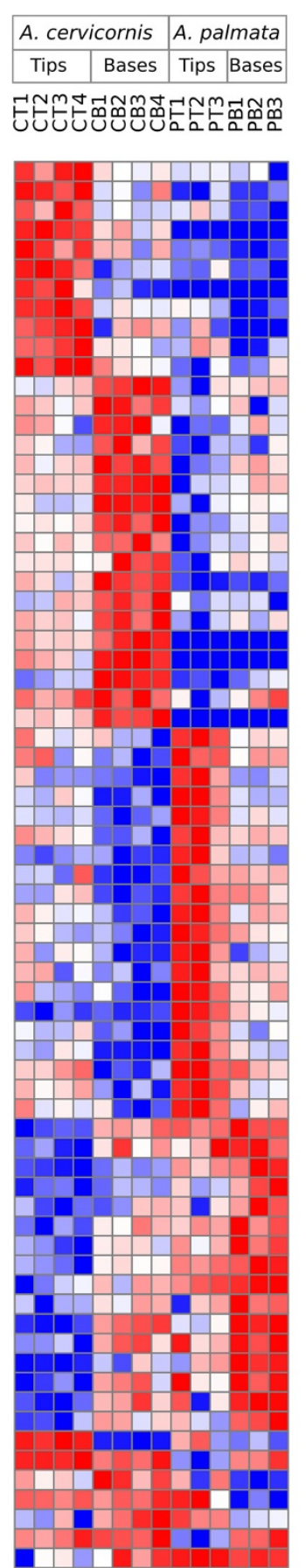

Apolipophorins

C-type lectin domain family 4 member $M$

Collagen triple helix repeat-containing protein 1

Williams-Beuren syndrome chromosomal region 27 protein

Thiamine biosynthesis multifunctional protein ThiED

Protein phosphatase 1 regulatory subunit 27

Predicted protein

Predicted protein

Predicted protein

Predicted protein

Predicted protein

Neurogenic locus notch homolog protein 1

Follistatin-related protein 4

Transient receptor potential channel

MAM domain-containing protein 2

Cartilage intermediate layer protein 1

Tenascin

Protocadherin Fat 2

Multiple epidermal growth factor-like domains protein 6

Protein DD3-3

Proto-oncogene tyrosine-protein kinase receptor Ret

Pecanex-like protein C14orf135 homolog

Chymotrypsinogen 2

Putative bifunctional amine oxidase DDB G0291301

Putative bifunctional am

Serine/threonine-protein kinase PDIK1L

Serine/threonine-p
Predicted protein

Predicted protein

Frizzled-6

Transcription factor SOX-9

Sodium-driven chloride bicarbonate exchanger

Papilin

Lysyl oxidase homolog 2

Succinate dehydrogenase flavoprotein subunit

Phospholipase A2 isozyme PA-12C

GFP-like fluorescent chromoprotein amFP486

Serine-aspartate repeat-containing protein I

Serine-aspartate repeat-containing protein $\mathrm{F}$

Enolase-phosphatase E1

Probable cysteine desulfurase

Hemicentin-1

Type I iodothyronine deiodinase

Substance-P receptor

Putative ATP-dependent CIp protease subunit

Cystathionine gamma-synthase

Putative uncharacterized protein

Predicted protein

Kinetochore protein SLK19

Retinol dehydrogenase 8

Crumbs homolog 1

Pogo transposable element with KRAB domain

Mannan-binding lectin serine protease 1

Apoptotic chromatin condensation inducer in the nucleus

Egg protein

Fibropellin-1

Sacsin

Sacsin

Putative L-amino-acid oxidase YobN

NFX1-type zinc finger-containing protein 1

NFX1-type zinc finger-containing protein 1

NFX1-type zinc finger-containing protein 1

NFX1-type zinc finger-containing protein 1

Predicted protein

LRP-1B*

Lectin BRA-3*

Sphingolipid delta(4)-desaturase/C4-hydroxylase DES2*

Protein DD3-3*

SE-cephalotoxin

Tomoregulin-2*

Predicted protein* row max

Uniprot ID

Q9U943

Q8HY12

Q8CG08

Q8N6F8

Q9D119

A7RUI4

A7RTB2

A7SCU4

A7SJ WO

A7TAX7

P 46531

Q93971

Q8CG85

075339

P24821

Q9DER5

Q5F226

075095

P07949

Q5HZQ9

P04813

Q54EW2

P81383

Q8N165

A7RGA3

A7RMG6

Q61089

018896

Q32LP4

Q 768860

Q13443

Q7ZVF3

P20256

Q9U6Y6

Q8KWM1

Q9K114

Q17Q32

Q96RW7

Q61153

P25103

088696

Q1MOP5

Q 3 ZGG5

A7SXL8

A7SXL8

Q085126

P82279

Q9P215

Q8CHN8

Q9UKV3

Q1HA50

P10079

Q9) LC8

Q9 LCC8

Q34363

Q8R 151

Q9P2E3

Q9P2E3

A7SK08

Q9NZR2

P07439

Q564G3

B2DCR8

Q9QYM9

Figure 5 Heat map of transcripts DE for both factors or the interaction between factors $\left(^{*}\right)$. Includes only transcripts with fold change $>2$, except for transcripts with a significant interaction effect.

polyps of the colony are the site of gamete synthesis and energy production via the photosynthesis carried out by their higher concentration of Symbiodinium. Asexual reproduction of polyps requires mitotic cell proliferation as well as regulation of cell identity through developmental signaling pathways. Production of the calcium carbonate skeleton is dependent on maintaining a high aragonite saturation state at the site of calcification [51] and controlling the shape of the precipitated biomineral, most likely through extracellular matrix (ECM) proteins. As expected, genes associated with these processes were significantly DE.

Some Gene Ontology (GO) Biological Process categories contained a relatively high number of $\mathrm{DE}$ genes for the 
colony position factor (Figure 6). Relevant categories include those involved in signaling and pattern development, metabolic processes, transport, and ECM. Categories containing many more genes up-regulated in tips include regulation of Wnt Signaling, translation, electron transport chain, ATP biosynthesis, ECM organization and collagen fibril organization. Cell-cell adhesion and calcium ion transport showed greater up-regulation in bases. To evaluate a broader number of biological functions, additional analyses were conducted based on UniProt annotation information and a review of the literature for DE genes showing greater than 2-fold difference in gene expression.

\section{Signaling and development}

There were pronounced patterns of DE signaling genes between branch tips and bases, particularly associated with three major signaling pathways, Wnt, Notch and Bone Morphogenetic Protein (BMP) (Table 1, Figure 7). These pathways are involved in pattern specification, cell fate commitment, establishment of tissue polarity, regeneration, and biomineralization and have previously been identified in cnidarians, such as Hydra, $N$. vectensis, and A. millepora [18,52]. Differential expression of these signaling pathways within the coral colony supports their roles in reef coral development, not only during embryonic and early polyp stages, but also throughout the life of the colony.

In addition, we observed a small number of genes associated with these signaling pathways that were DE for both colony position and species factors. We propose that these intercellular signaling pathways, particularly Wnt signaling, may play an important role in organizing the asexual development of new polyps at branch tips and in regulating the branching patterns of $A$. cervicornis versus $A$. palmata.

\section{Wnt signaling pathway}

Wnt signaling functions via the interaction of Wnt ligands and two types of receptor molecules, Frizzled (Fzd) receptors and low-density lipoprotein co-receptors. Wnt pathway inhibitors include Dickkopf proteins (Dkk), Wnt inhibitory factor and secreted Frizzled-Related Proteins. Studies in multiple cnidarian species, including Hydra, N. vectensis, Clytia hemisphaerica and Hydractinia echinata, indicate that expression of Wnt and Dkk proteins are involved in oral/aboral axis formation, head regeneration and tentacle formation [24,27,28,53-55]. Wnt signaling also appears to direct axial patterning in cnidarian larva, playing a similar role to that of Hox signaling in bilaterians [12]. A number of Wnt genes DE in this dataset are either associated with developmental regulation in cnidarians or have been implicated in regulating biomineralization or cartilage formation in vertebrates (Table 2), suggesting that in calcifying corals Wnt signaling may also participate in skeleton formation.

Fourteen Wnt-related genes were DE between colony bases and tips for both species. The majority of these transcripts were more highly expressed in branch tips (wnts 2, 2b, 5a, 5b, $8 a \mathcal{E} 8 b$, lrp1, krem1, and $d k k 3$ ), but five genes showed higher expression in colony bases (wnts $7 a$ \& $7 b$, lrp6, sox 17 and casein kinase I). One putative Wnt regulatory gene, dickkopf-related protein 3 (dkk3), was represented by four transcripts exhibiting high up-regulation in branch tips (3.4-7.5 fold change). Although $d k k 3$ has shown some Wnt-related activity in

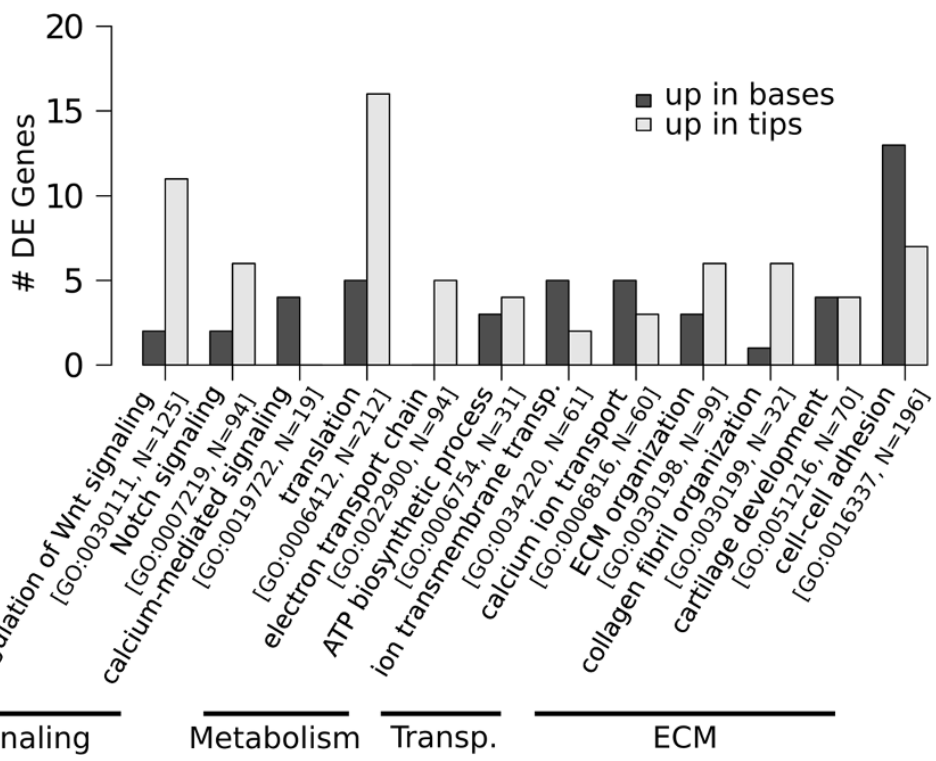

Figure 6 GO term summary of DE genes for colony position. Values represent the number of transcripts with $>2$-fold change in gene expression for selected 'enriched' GO Biological Process terms. N is the total number of transcripts in the dataset annotated with the given GO term. 
Table 1 Genes from developmental signaling pathways

\begin{tabular}{|c|c|c|c|c|c|c|c|}
\hline Signaling pathway & Gene family & Reference & Dataset & Pos. & Both & Int. & Trend \\
\hline \multirow[t]{14}{*}{ Wnt } & Wnt proteins & $13(27)$ & $10(17)$ & 8 & - & - & Up tips \\
\hline & Frizzled & $8(16)$ & $8(12)$ & - & 1 & - & Up A. palm tips \\
\hline & Fzd-related & $2(4)$ & $2(4)$ & 1 & - & - & Up tips \\
\hline & LRP & $9(45)$ & $8(25)$ & 1 & - & 1 & Up A. cerv tips \\
\hline & Kremen & 1 & 1 & 1 & - & - & Up tips \\
\hline & Dkk3 & $1(6)$ & $1(6)$ & 4 & - & - & Up tips \\
\hline & Sox9 & $1(2)$ & $1(2)$ & - & 1 & - & Up A. palm tips \\
\hline & Ror2 & $1(3)$ & $1(3)$ & - & - & - & - \\
\hline & Axin & 1 & 1 & - & - & - & - \\
\hline & B-catenin & 1 & 1 & - & - & - & - \\
\hline & GSK-3ß & $1(2)$ & $1(2)$ & - & - & - & - \\
\hline & Dishevelled & 1 & 1 & - & - & - & - \\
\hline & Sprouty & $2(3)$ & $2(3)$ & - & - & - & - \\
\hline & Wnt inhibitory factor & $1(2)$ & 1 & - & - & - & - \\
\hline \multirow[t]{7}{*}{ Notch } & Notch & $5(53)$ & $5(23)$ & 5 & 1 & - & Up A. cerv tips \\
\hline & Delta/Delta-like & $6(10)$ & $2(3)$ & - & - & - & - \\
\hline & Jagged & $4(8)$ & $3(4)$ & - & - & - & - \\
\hline & Hairy/enhancer of split & $1(3)$ & $1(3)$ & - & - & - & - \\
\hline & E3 ubiquitin ligase MIB & $2(18)$ & $2(14)$ & 1 & - & - & Up bases \\
\hline & Suppressor of hairless & $2(2)$ & $2(2)$ & - & - & - & - \\
\hline & Numb & 1 & 1 & - & - & - & - \\
\hline \multirow[t]{3}{*}{ BMP } & BMP & $7(15)$ & $4(10)$ & 1 & - & - & Up bases \\
\hline & BMP receptor & $2(2)$ & $2(2)$ & - & - & - & - \\
\hline & Chordin/chordin-like/kielin & $3(9)$ & $3(9)$ & 1 & - & - & Up bases \\
\hline
\end{tabular}

Number of genes (transcripts in parentheses) found in annotated coral transcriptome (Reference), and in the dataset. Numbers of DE genes for colony position (Pos.) and both factors (Both) indicate transcripts with $>2$-fold change in expression.

bilaterians, in cnidarians there is evidence that $d k k 3$ facilitates migration of mature cnidocytes from the gastric region towards the tentacles [61].

Four putative Wnt pathway transcripts were significantly DE for both species and colony position, all of which were up-regulated in branch tips. Two transcripts were significantly up-regulated in A. cervicornis branch tips, collagen triple helix repeat-containing protein 1 (cthrc1) and apolipophorins, and two were up-regulated in $A$. palmata branch tips, $f z d 6$ and sox9. Another gene, lowdensity lipoprotein receptor-related protein, $\operatorname{lrp} 1 b$, which was DE by colony position and significant for the interaction between factors, is closely related to LRP1, a Wnt regulator [70]. $\operatorname{lrp} 1 b$ was more highly expressed in tips of both species but to a much greater degree in A. cervicornis (110-fold) than $A$. palmata (8-fold change).

\section{Notch signaling pathway}

Canonical Notch signaling occurs between adjacent cells and involves a transmembrane surface receptor (Notch) that interacts with membrane-bound ligands
(Delta-Serrate-LAG2) on neighboring cells [71]. Activation of Notch is associated with maintaining the undifferentiated state of cells, while suppression of Notch is required for cells to progress toward a specific cell fate [71]. In cnidarians, Notch signaling is involved in asexual budding and tentacle formation, as well as development of neural cells, oocytes and cnidocytes, as shown in developing Hydra [16,72] and N. vectensis [17]. However, Hydra and $N$. vectensis are both non-calcifying cnidarians and Notch may have additional roles in calcifying corals. The effect of Notch signaling may also be influenced by interactions with Wnt and TGFß/BMP signaling pathways [73,74].

Eighteen transcripts in the Notch signaling pathway were DE by colony position and were usually up-regulated in tips. In our dataset, notch1 and notch 2 transmembrane protein genes and a regulatory gene, GDP-mannose 4,6, dehydratase, were consistently up-regulated in tips, while one Notch regulatory gene, E3 ubiquitin-protein ligase $M I B 2$, was up-regulated in bases. One Notch transcript (notch1), which was up-regulated in A. cervicornis base samples, was significantly DE for both factors. 


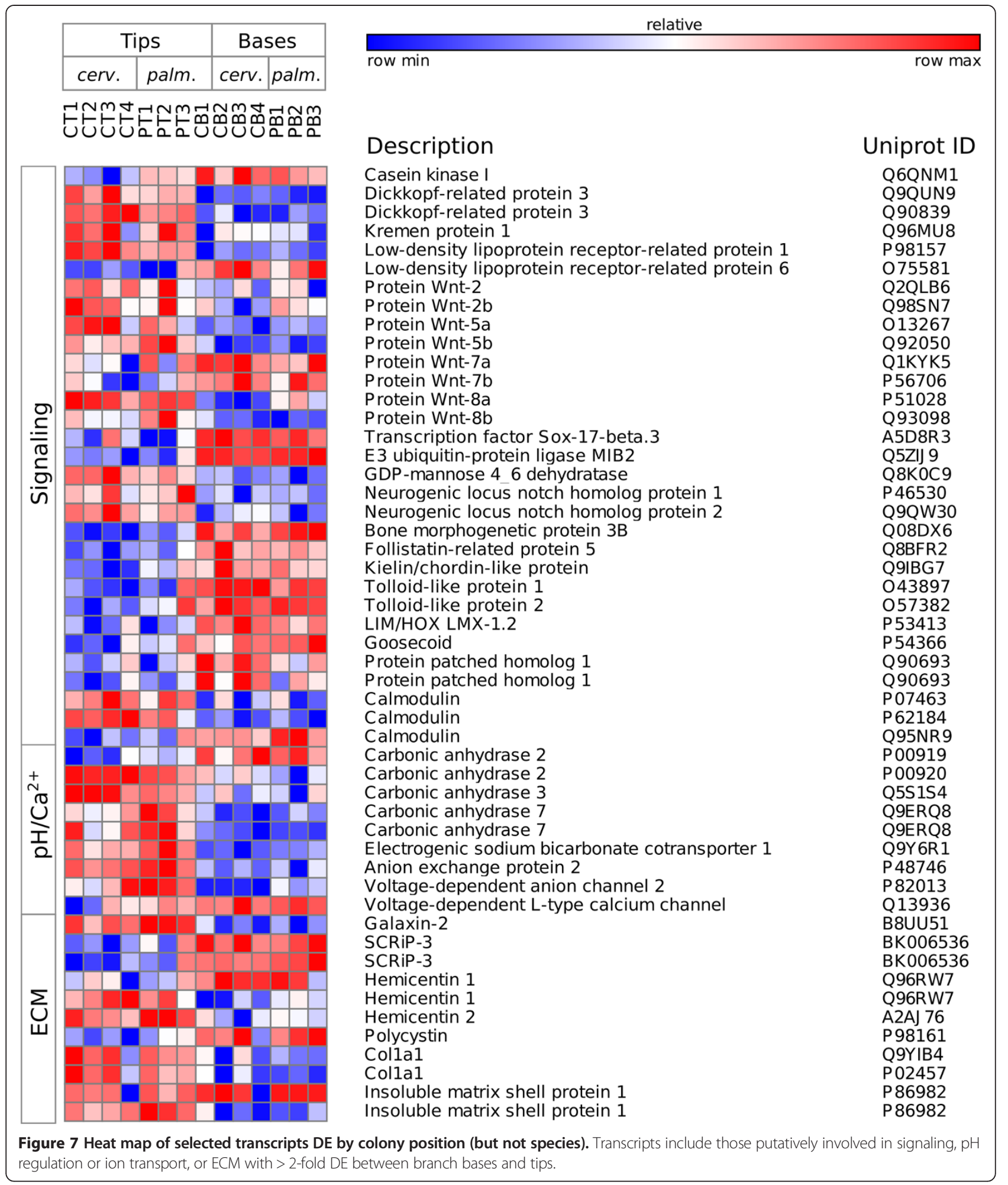

Bone morphogenetic protein signaling pathway

BMPs are secreted signaling molecules that bind to transmembrane BMP receptors (I \& II) and initiate a downstream signaling cascade regulating the expression of target genes. BMP inhibitors include chordin, noggin, and intracellular inhibitory proteins, while tolloid-like proteins may cleave chordin to enhance signaling [75]. All six BMP-associated DE genes for colony position showed higher expression in branch bases (bmp3b, follistatinrelated protein 5, kielin/chordin-like protein, tolloid-like 
Table 2 Summary of selected DE Wnt pathway genes

\begin{tabular}{|c|c|c|c|c|}
\hline Gene & Expression higher in: & Functions \& interactions & Study system & Ref. \\
\hline Wnt2, 2a, NvWnt2 (AAW28132) & Tips & Oral/aboral axis determination & N. vectensis & [12] \\
\hline \multirow[t]{2}{*}{ Wnt5a } & Tips & Oral/aboral axis determination (NvWnt5) & N. vectensis & [12] \\
\hline & & Bud/tentacle formation (hvwnt5) & Hydra & {$[56]$} \\
\hline \multirow[t]{2}{*}{ Wnt7a, 7b, NvWntA (AAT02182) } & Bases & Oral/aboral axis determination (NvWntA; NvWnt7) & N. vectensis & [12] \\
\hline & & Bud formation/head regeneration (HyWnt7) & Hydra & {$[57]$} \\
\hline Wnt8a, 8b, 5b, NvWnt8b (AAW28136) & Tips & Bud/tentacle formation (hvwnt8) & Hydra & {$[56]$} \\
\hline \multirow[t]{2}{*}{ Krem1 } & Tips & Interaction w/Dkk3 & Amphioxus & {$[58]$} \\
\hline & & & Human cells & [59] \\
\hline \multirow[t]{2}{*}{ Dkk3 } & Tips & Regulation of biomineralization \& beak shape; & $\begin{array}{l}\text { Darwin's finches } \\
\text { (Geospiza spp.) }\end{array}$ & {$[60]$} \\
\hline & & Migration of mature cnidocytes & Hydra & {$[61]$} \\
\hline LRP6 & Bases & Bone formation & Mouse & Review [62] \\
\hline \multirow[t]{2}{*}{ Cthrc1 } & A. cerv tips & Activates Wnt-PCP pathway; & Mouse & [63] \\
\hline & & Inhibits type 1 collagen; BMP4 \& TGF-ß signaling & Mouse and rat & [64] \\
\hline Apolipophorins & A. cerv tips & $\begin{array}{l}\text { Inter-cellular transport of Wnt \& Hedgehog } \\
\text { signaling molecules }\end{array}$ & Drosophila & [65] \\
\hline \multirow[t]{2}{*}{ Fzd6 } & A. palm tips & Represses canonical Wnt signaling; & Human cells & [66] \\
\hline & & Nail/claw formation & Mouse & {$[67]$} \\
\hline \multirow[t]{2}{*}{ Sox9 } & A. palm tips & Cartilage development & Mouse cells & [68] \\
\hline & & & Mouse & [69] \\
\hline LRP1, 1b & Tips \& interaction & Regulates Wnt pathway & Human cells & [70] \\
\hline
\end{tabular}

Genes include those with roles in cnidarian development and/or cartilage development and biomineralization in other organisms, as well as genes for putative Wnt-interacting proteins. Putative functions and interactions are based on the references. Closest identified cnidarian homolog and GenBank accession ID included for Wnt proteins where applicable.

protein ( $t l l) 1 \in$ \& 2 , and transcription factor scleraxis), revealing the opposite pattern from Wnt and Notch signaling pathways. One potential BMP-related gene, follistatin-related protein 4 (fstl4), which shares similarities with follistatin, a BMP inhibitor [76], was DE for both factors and was up-regulated in $A$. cervicornis bases.

BMP signaling, specifically via BMP $2 / 4$, chordin and tolloid, is important in the dorsal-ventral (D-V) axis determination of bilaterians [77,78]. bmp2/4 and chordin show localized expression during cnidarian larval development [79-81], and BMP2/4 has also been localized to the calicoblastic epithelium of mature corals, suggesting involvement in skeleton formation [15]. As its name suggests, BMP is often associated with bone growth and biomineralization, and the combined effects of BMP4 and calmodulin have been proposed to determine the overall length and width of bird beaks and fish jaws [82]. The differential expression of BMP signaling pathway (up-regulated in bases) and calmodulin (two transcripts up in tips, one up in bases; see calcium signaling) may be involved in coral biomineralization as well. Interestingly, the only BMP protein DE by colony position was $b m p 3 b$, which was up-regulated in bases. In vertebrate models, BMP3 and BMP3b function differently than other BMP proteins and are antagonists of osteogenic BMP2 [83-85].
Consequently, lower $b m p 3 b$ expression in branch tips may enhance activity of other BMP proteins that were not DE by colony position, including BMP2/4.

\section{Other developmental signaling pathways}

Hox genes encode homeodomain-containing proteins, regulatory proteins that direct patterning and identity of embryonic regions in animals. In cnidarians, some Hox/ ParaHox genes appear to be involved in anterior/posterior patterning during larval development, development of sensory cells [9], and determination of polyp morphotype (cnox2) [32]. Most of the Hox/ParaHox genes DE by colony position, including Hox/LIM proteins, goosecoid, paired-like, and six3/6 homeobox genes [86-89], have likely roles in larval or polyp development. Some transcripts annotating to Hox or Hox-like genes were DE in this dataset, yet none were DE for both factors with $>2$-fold change, suggesting that these genes function similarly in both $A$. cervicornis and A. palmata.

Two forkhead domain containing proteins and a Hedgehog pathway receptor were DE by colony position. Some forkhead box proteins are involved in embryonic development of Hydra [90] and N. vectensis [91], and many forkhead transcription factors interact with other signaling pathways, including Wnt, TGF-ß, and Hedgehog 
[92]. patched homolog 1, a Hedgehog pathway receptor associated with the divergence of jaw morpohologies in cichlid fishes [93], was up-regulated in branch bases.

\section{Calcium signaling}

Calcium signaling relies on the gradient of calcium ions, rather than biomolecules, and is found in both prokaryotes and eukaryotes [94]. In cnidarians calcium signaling may affect multiple functions including reproduction [95], nematocyst regulation [96] and biomineralization [97]. Eight calcium signaling genes were DE by colony position. While GO term analysis indicated up-regulation of calcium signaling in bases, this is misleading because a number of calcium signaling-related genes up-regulated in tips were not annotated with this GO category, including calmodulin, dysferlin and delta-latroinsectotoxin-Lt1a. Both delta-latroinsectotoxin-Lt1a, a putative toxin [98], and its likely receptor, latrophilin-1, were up-regulated in branch tips. Five calcium signaling genes up-regulated in bases included a transcript of calmodulin, metabotropic glutamate receptor 1, extracellular calcium sensing receptor, calcium/calmodulin dependent protein kinase, and Eselectin. Calmodulin is a highly-conserved calcium-binding protein that interacts with other proteins to facilitate calcium signaling and is associated with shaping craniofacial morphology of some bird and fish species [82,99,100].

\section{Skeleton deposition}

Skeletal growth in Acropora proceeds by a lattice-like arrangement of extending parallel 'rods' and reinforcing perpendicular 'bars' that construct the corallite $[5,101,102]$. Corallites of $A$. cervicornis are comprised of four concentric rings of skeleton [5], while those of A. palmata contain three concentric rings (Gladfelter, E. H., personal communication). The linear extension growth rates of these two species have been estimated at $6.5-20 \mathrm{~cm} / \mathrm{yr}$ for $A$. cervicornis and 5-10 cm/yr for A. palmata [103-105], with A. cervicornis also demonstrating a faster rate of calcium deposition ( $\mu \mathrm{g} \mathrm{Ca/mg} \mathrm{N/hr)} \mathrm{[39].} \mathrm{Despite} \mathrm{the} \mathrm{broader}$ branches of $A$. palmata and its ability to withstand higher wave energy, skeletal construction in A. cervicornis is stronger and slightly less porous [106]. Our results, described below, suggest that many of the putative calcification genes are similarly expressed between species, such as carbonic anhydrase (CA), calcium ion transport proteins and ECM proteins like galaxin. Differences between species may be related to bicarbonate transport or ECM proteins that have been linked to coral skeleton or biomineralization in other organisms.

\section{Regulation of $\mathrm{pH}$, carbonate and calcium}

In scleractinian corals, mineralization of calcium carbonate occurs beneath the calicoblastic epithelium as the conversion of calcium ions and carbonate to the aragonite form of calcium carbonate $\left(\mathrm{Ca}^{2+}+\mathrm{CO}_{3}^{2-} \rightarrow \mathrm{CaCO}_{3}\right)$ [107]. In practice the source of inorganic carbon for calcification may also be bicarbonate $\left(\mathrm{Ca}^{2+}+\mathrm{HCO}_{3}^{-} \rightarrow\right.$ $\left.\mathrm{CaCO}_{3}+\mathrm{H}^{+}\right)$or carbon dioxide $\left(\mathrm{Ca}^{2+}+\mathrm{CO}_{2}+\mathrm{H}_{2} \mathrm{O} \rightarrow\right.$ $\mathrm{CaCO}_{3}+2 \mathrm{H}^{+}$), both of which produce protons that must be removed from the site of calcification [107]. Corals actively contribute to calcification through $\mathrm{CA}$ activity (interconversion of $\mathrm{CO}_{2}+\mathrm{H}_{2} \mathrm{O}$ and $\mathrm{HCO}_{3}^{-}+\mathrm{H}^{+}$), and by regulating proton (i.e. $\mathrm{pH})[108,109]$ and calcium ion concentrations [109-111] within the calicoblastic epithelium and in the sub-epithelial space. Previous work has confirmed the presence and importance of CAs, anion channel, and calcium channel proteins in coral calcification and within the calcifying tissues [34,112-114]. Though calcium ion transport across the oral epithelial layers occurs via passive diffusion in some species [115], energy-driven calcium transport across the calicoblastic epithelium is believed to involve an L-type $\mathrm{Ca}^{2+}$ channel protein and $\mathrm{Ca}^{2+}$-ATPase coupled with an anion carrier to transport calcium ions across the oral calicoblastic epithelial membrane $[109,115,116]$ and a PMCA-type calcium pump [117] to transport calcium to the extracellular calcifying site. We found that CA, bicarbonate transport, and calcium ion transport transcripts were DE by colony position.

As expected for the location of rapid calcification, $C A$ activity (CAs 2, 3 \& 7) was highly up-regulated in branch tips, though one transcript (CA2) was up-regulated in bases. No $C A$ transcripts were DE for both factors. In corals, it has been proposed that CAs function to provide increased inorganic substrates for both skeleton formation (bicarbonate) [113] and symbiont photosynthesis (carbon dioxide) [118], which may explain up-regulation of CA2 in branch bases.

One inorganic carbon transport protein, electrogenic sodium bicarbonate transporter 1 (SLC4A4), was upregulated in tips, while one, sodium-driven chloride bicarbonate exchanger (SLC4A10), was DE for both factors. $S L C 4 A 10$, which was up-regulated in $A$. palmata tips, imports bicarbonate and sodium into the cell. In corals sodium-driven bicarbonate exchangers may regulate $\mathrm{pH}$ and supply bicarbonate for calcification [47]. A number of other ion transporters were DE by colony position. Those up-regulated in tips included anion exchange proteins, potassium channels and sodium/potassiumtransporting ATPases. Those up-regulated in bases include an organic cation transporter, four solute carriers, and a cation channel.

Calcium transport may be involved directly in transporting calcium ions to the site of skeleton deposition, but may also be related to calcium signaling. A voltagedependent L-type calcium channel protein was DE by colony position, but was up-regulated in branch bases. Three transcripts of VWFA and cache domain containing 
protein (cachd1), which may be involved in regulating voltage-dependent calcium channels, were DE by colony position (two transcripts were up-regulated in bases, one in tips). Transcripts of $\mathrm{Ca}^{2+}$-ATPase were observed in the dataset, but none was DE by colony position. Another transcription-based study of acidification found no change in the expression of $\mathrm{Ca}^{2+}$-ATPase in response to $\mathrm{CO}_{2}$-driven acidification [49]. One calcium transport gene was $\mathrm{DE}$ for both factors. transient receptor potential channel, a calcium entry channel, was up-regulated in $A$. cervicornis bases. A similar gene was previously found to be down-regulated in A. millepora in response to ocean acidification [49].

Extracellular matrix (ECM) \& skeletal organic matrix (SOM) The aragonite crystals that form at the margins of growing coral skeleton resemble abiotically precipitated calcium carbonate, leading some to suggest that coral skeletal growth is independent of SOM $[119,120]$, yet many studies suggest a role for SOM in some form [121-127]. ECM proteins can be incorporated into the skeleton (as skeletal organic matrix; SOM) and/or provide a structured boundary for the growing skeleton. SOM is believed to control skeletal growth by either inducing or inhibiting nucleation of biomineral crystals, but some SOM proteins may be components of epithelial ECM and cell-adhesion proteins that become incorporated into the skeleton as it grows.

Until recently only one SOM protein, galaxin, had been characterized from a scleractinian coral [122], yet a number of putative SOM constituents have been proposed, including small cysteine-rich proteins (SCRiPs) [128], unidentified proteins or short peptides with high acidic amino acid (aspartic acid and glycine) content [125], glycosaminoglycans [125], lipids [129], and chitin [130,131]. Recently, 36 SOM proteins were extracted and identified from $A$. millepora skeleton, suggesting roles for numerous functional proteins in biomineralization, including ECM-cell adhesion proteins, enzymes, acidic proteins, and a toxin [127].

\section{ECM: within colony differences}

One galaxin, galaxin-2, was up-regulated in tips of both species, while another galaxin was not DE for either factor. Previous studies have noted that some galaxin-related genes are expressed at different stages of development [132] or respond differently to elevated $\mathrm{CO}_{2}$ [49], supporting distinct roles for various galaxins in calcification or other functions. Two SCRiP-3 transcripts were also DE, but were up-regulated in bases. SCRiPs are coral-specific proteins of unknown function, but their cysteine-rich composition has been suggested as a possible mode of interaction with the SOM protein galaxin [128]. SCRiP-3 gene expression has previously shown association with larval development $[133,134]$, as well as localization to developing skeletal septa [133]; however, up-regulation of
SCRiP-3 in bases suggests it is not involved in rapid calcification in branch tips of $A$. cervicornis. A number of genes DE by colony position resembled those characterized in A. millepora, including a mucin, hemicentin, polycystin-1, protocadherins and collagen type I alpha I. Additional ECM genes that were DE, including proteoglycan, glycoprotein and endopeptidase transcripts, may regulate cell-cell or cell-matrix interactions that guide coral growth; however, further studies are needed to determine why these genes were $\mathrm{DE}$, since they may have alternate roles in corals.

One mucin, integumentary mucin C.1, was up-regulated in tips and may also serve as a component of the ECM or even play a role in biomineralization, as they do in molluscs [135]; however, mucins are used by corals for feeding, as a physical barrier against microbes and physical stresses [136]. Four hemicentin (1 and 2) transcripts were DE by colony position, but with up-regulation in tips and bases. In corals, hemicentin is involved in hemidesmosome-mediated attachment of the calicoblastic epithelium to the skeleton [137]. As the skeleton grows, hemicentin may become incorporated with the deposited aragonite [138]. Four cadherins or protocadherins were DE by colony position. One gene, protocadherin Fat 3, was up-regulated in tips, and three genes, protocadherin Fat 4, protocadherin-23, and cadherin EGF LAG seven-pass G-type receptor 3, were up-regulated in bases. Cadherins form adherens junctions, regulate cell adhesion, mobility and communication, but also interact with $\beta$-catenins and are one way in which Wnt proteins may be involved in mediating cell-cell interactions [69].

Only one collagen (col1a1) has been characterized from A. millepora SOM, but our data indicate that a large number of additional collagens are involved in coral growth. This is not surprising given that collagens comprise about $30 \%$ of the total protein content of animals. Twelve collagen transcripts were DE by colony position, with the majority $(n=11)$, including colla1, more highly expressed in tips. In addition, four collagen-interacting genes were up-regulated in tips, including loxl2, transmembrane prolyl 4-hydroxylase (P4H-TM), collagenase 3 and fibronectin, and two were up-regulated in bases, procollagen $C$-endopeptidase enhancer 1 and peroxidase mit-7.

Eleven proteoglycan and proteoglycan synthesis genes were DE by colony position. These included two transcripts of insoluble matrix shell protein 1 (ISMP-1) that were up-regulated in bases and one transcript up-regulated in tips. ISMP-1 was originally identified as a component of the organic matrix in the calcified shell of the Manila clam, Venerupis philippinarum, and may represent a conserved biomineralization protein [139]. Six glycoproteins were significantly DE by colony position, including uromodulin (Tamm-Horsifall protein), which had two transcripts up- 
regulated in bases. Uromodulin controls crystal formation in the vertebrate urinary tract and may act as a mineralization inhibitor during skeleton formation, but it has also been implicated in symbiont interactions in non-calcifying cnidarians [140].

\section{ECM: differences between species}

Three ECM proteins, similar to those found in coral SOM [127], were DE for both factors or showed an interaction between factors. hemicentin-1, was up-regulated in $A$. palmata branch tips. A protocadherin (Fat 2) transcript was most highly expressed in A. cervicornis bases. And a gene annotated as cephalotoxin from the squid Sepia esculenta showed an interaction between factors, though it was not significantly DE for either; it was up-regulated in branch bases of $A$. cervicornis but branch tips of $A$. palmata.

Since no collagen genes were DE for both factors, direct gene expression of collagens does not appear to determine the morphological differences between A. cervicornis and A. palmata; however, two collagen-interacting protein genes were up-regulated in branch tips as well as being DE for species. cthrc1, a secreted glycoprotein with putative roles in regulating deposition of extracellular collagen matrix and Wnt signaling, was up-regulated in A. cervicornis tips, and lysyl oxidase homolog 2 (loxl2), which may have a role in collagen processing, was upregulated in A. palmata tips.

Two C-type lectins were most highly expressed in $A$. cervicornis tips, one of these, Lectin BRA-3, is believed to be involved in biomineralization in barnacles and has been shown to either inhibit or promote crystal growth of calcium carbonate in vitro, depending on the conditions [141-143]. Lectins have numerous functional roles in animals, including cell adhesion, glycoprotein synthesis, and immunity and may regulate host-symbiont interactions in cnidarians $[50,144,145]$.

\section{Growth \& metabolism}

Increased cellular activity in branch tips was indicated by high expression of genes associated with aerobic respiration and translation relative to branch bases. This is consistent with the observed higher metabolic rate at the tip of Acropora branches, relative to the bases [40]. However, cytoskeletal construction was up-regulated in branch bases, and genes related to ATP biosynthesis, carbohydrate and lipid metabolic processes were upregulated both in tips and bases.

Consistent up-regulation of translation in tips of both species was indicated by a large number $(n=16)$ of moderately elevated ( $\sim$-fold) ribosomal protein (RP) transcripts, only two RPs were up-regulated in bases. Elevated aerobic respiration in tips was indicated by increased expression of five genes involved in the mitochondrial electron transport chain. One gene, a succinate dehydrogenase, was DE for both factors and was most highly expressed in A. palmata tips. Cytoskeletal construction was up-regulated in branch bases. Almost all cytoskeleton-related genes (including actin, tubulin and dynein) that were DE by colony position $(n=31)$ were up-regulated in bases $(n=27)$. Only four transcripts of cytoskeleton genes were up-regulated in tips (neurofilament medium polypeptide, girdin, tubulin alpha-1D chain, and spectrin).

Sphingolipid metabolism was the most prominent DE lipid biosynthesis pathway. Sphingolipids are lipids with a backbone of sphingoid bases that form a protective layer outside of the cell membrane, and complex glycosphingolipids can be involved in cell recognition, signaling, and immunity. Three genes involved in sphingolipid metabolism were DE by colony position with two upregulated in tips (alkaline ceramidase and galactosylceramide sulfotransferase) and one up-regulated in bases (ceramide kinase). One transcript, sphingolipid delta(4)desaturase/C4-hydroxylase DES2 (DEGS2), was DE by species with a significant interaction effect, showing highest expression in A. cervicornis bases and lowest expression in A. palmata bases. In cnidarians, sphingolipids appear to be involved in stability of the coral-Symbiodinium relationship and may determine whether heat stress results in coral bleaching [146].

Genes involved in the biosynthesis of fatty acids showed a pattern of up-regulation in bases, but lipid catabolic processes appeared to be up-regulated in tips. Three genes involved in building fatty acid chains (fatty acid synthase, acetyl-CoA carboxylase 1, and acyl-CoA desaturase) were up-regulated in bases and at least three genes involved in fatty acid beta-oxidation (short-chain specific acyl-CoA dehydrogenase, hydroxyacyl-coenzyme A dehydrogenase and long-chain-fatty-acid-CoA ligase 5) were up-regulated in tips. Fatty-acid molecule production in bases may serve two functions: corals may store energy produced by the higher photosynthetic activity of Symbiodinium as fatty-acids [147], and/or radial polyps increase production of fatty acids to meet the high lipid demand of egg development [148], which is likely to be higher during the summer spawning season. Another lipid metabolism gene, phospholipase A2 isozyme PA-12C, which could function in the arachidonic acid pathway, in repairing oxidized membrane lipids [149] or as a toxin in the nematocyst complex $[150,151]$, was DE for both factors and most highly expressed in $A$. palmata tips.

\section{Response to light \& stress}

As sessile animals, Acropora corals are unable to change location (unless disrupted or broken by external forces) and therefore respond to environmental stimuli and stresses physiologically. Acropora corals use light cues (blue light of 
408-508 $\mathrm{nm}$ ) to determine their direction of growth and to initiate axial polyp development [152], and like other corals, they may also use light to adapt their polyp behavior [153] and coordinate spawning [154,155]. Living in relatively shallow waters, Caribbean Acropora are exposed to high levels of UV and heat stress, as well as oxidative stress resulting from metabolism and photosynthesis. A number of light and stress response genes were DE between tips and bases, and interestingly genes DE for both factors were consistently up-regulated in $A$. palmata. This is likely due to $A$. palmata being located in shallower water and exposed to higher levels of UV light compared to A. cervicornis, thus requiring a greater response of chaperone proteins and potentially photoprotective pigment (GFP-like) [156,157].

Two photoreceptor genes that could be involved in phototropic growth, retinol dehydrogenases (rdhs) 7 and 8 , were up-regulated in tips. Rdhs convert retinol to retinal, a polyene chromophore involved in animal vision. In $A$. millepora, expression of $r d h$ decreased in response to transfer into laboratory conditions, likely in response to lower light conditions [158], but increased in response to heat stress [159]. Two melatonin receptors were DE by colony position. Melatonin receptor type $1 B-B$ was up-regulated in tips, and melatonin receptor type $1 A$ was up-regulated in bases. Melatonin production is light dependent, with increased production at night being a primary regulator of circadian rhythm in vertebrates. Melatonin has been shown to affect expansion of oral disc in sea anemone polyps (Actinia sp.) [160] and may be involved in polyp behavior. In Caribbean Acropora, polyp behavior during the day differs between radial and axial polyps; symbiont-rich radial polyps are active throughout the day to photosynthesize, but axial polyps are only extended at night to feed. Two genes involved in photoreception, $r d h 8$ and crumbs homolog 1 , were DE for both factors, and both were most highly expressed in A. palmata bases.

Heat shock proteins (HSPs) function during times of stress, such as at elevated temperatures, when other proteins may become denatured. One HSP, HSP70, was DE by colony position and was up-regulated in bases. Two transcripts of $\operatorname{sacsin}$, a DNAJ/HSP40 protein that acts as an HSP70 co-chaperone, were DE for both factors and most highly expressed in A. palmata bases. While HSPs protect cells from stress-related damage and may be up-regulated in bases due to higher levels of ROS during the day resulting from photosynthesis, HSP70-related genes have also been shown to interfere with Wnt-related axial development in cnidarians [161]; therefore, lower expression of these genes in tips may actually prevent interference with proper polyp development.

Another group of proteins showing differential expression were antioxidants that may be involved in redox response. Three putative antioxidants were up-regulated in tips, including thioredoxin domain-containing proteins (5 $\& 12$ ) and selenoprotein $W$. One putative stress response protein, a cyan-emitting GFP-like fluorescent chromoprotein (amFP486), was DE for both factors and up-regulated in $A$. palmata tips. GFP-like pigment proteins, which were also found to be up-regulated in branch tips of $A$. millepora [44], are thought to provide protection from strong UV radiation $[156,157]$.

\section{Cnidarian-specific gene expression}

Known cnidarian-specific genes that exhibited differential expression were those involved in cnidocyte and nematocyst development. Nematocysts are barb-containing cnidocysts that fire in response to mechanical stress to capture zooplankton prey or as defense. These organelles are comprised of an outer wall of nematocyst outer wall antigen (NOWA) and an inner wall of minicollagen containing a barb and stored toxins [162]. A number of transcripts annotating to genes involved in nematocyst development showed increased expression in branch tips, including two minicollagen transcripts, two NOWA transcripts, and a nematoblast-specific protein transcript.

Coral homologs of $N$. vectensis predicted proteins with no additional known function accounted for 92 transcripts $\mathrm{DE}$ by colony position, nine that were DE for both factors and one that was DE for species with a significant interaction. These may be cnidarian specific genes deserving of additional investigation.

\section{Division of labor within the coral colony}

Within the Acropora coral colony there is strong DOL between the actively growing branch tips and the radial polyps of branch bases. Increased expression of transcripts within our data is similarly divided between these regions, indicating that both sections of the coral branch are actively regulating different genetic processes. The high number of DE genes within colonies suggests greater differentiation among polyps in Caribbean Acroporas than was previously found for A. millepora [44]. This may be a true difference due to the contrast in colony structure between the much smaller $A$. millepora and the longer branches of Caribbean Acroporas, which may affect the extent to which polyps display functional differences, or it may be a function of technique (high-throughput RNA sequencing vs. microarray containing 2700 UniGene ids). However, the DOL observed in our study between branch tips and bases appears not to be as distinct as in some hydrozoans, as the proportion of total transcripts $(2,215 / 22,320=10 \%)$ DE by colony position is less than that found between functionally different siphonophore zooids $(3,558 / 19,534$ transcripts $=18 \%)$ [4].

Classical developmental signaling pathways (Wnt, Notch and BMP) were highly DE between branch tips and bases, 
indicating roles in the growth of mature coral colonies. In particular, up-regulation of a number of Wnt-related genes in branch tips, where new radial polyps are being produced, suggests that this signaling pathway is involved in asexual polyp budding in colonial Acropora corals. In other cnidarians, expression of Wnt signaling genes correlates strongly with the location of oral structures and appears to determine where tentacles and buds are produced [24,26-28,54,57]. In cnidarians, Notch signaling has been studied in much less depth than Wnt signaling; however, it appears to be important during development for proper cell fate determination, neurogenesis, and for establishing tissue boundaries during the budding of new polyps $[16,17,72]$. Up-regulation of Notch signaling in branch tips may be related to any of these putative functions.

Studies of BMP signaling in cnidarians are also limited, but BMP genes show localized expression in developing embryos and appear to be involved in axis determination and gastrulation [79-81]. In mature cnidarians, bmp2/4 is preferentially expressed in the cells that regulate skeleton deposition in corals, the calicoblastic epithelium [15]. Both Wnt and BMP pathways may affect skeleton formation, as related genes are known regulators of bone morphology and biomineralization in some vertebrate species (e.g. LRP6, Fzd6, Dkk3, BMP) [62,67,99]. Whereas Wnt and Notch signaling were up-regulated in branch tips, BMP genes were primarily up-regulated in branch bases. Interestingly, the primary BMP proteins studied in cnidarians (BMP2/4 and BMP5-8) were not DE, rather genes with putative regulatory roles were up-regulated in bases, including bmp3b, chordin, tolloid, follistatin and scleraxis. Additionally, calcium signaling via calmodulin, a DE calcium signaling gene known to determine morphology in vertebrates $[99,100]$, may influence biomineralization of the coral skeleton. Because crosstalk among signaling pathways is common [73,74,163,164], it is likely they are not functioning independently.

Skeletal growth by deposition of calcium carbonate occurs more rapidly in the branch tips, where we expect genes involved in calcification to be up-regulated. Though we did not observe increased expression of $\mathrm{Ca}^{2+}$-ATPase, a calcium transport protein suspected to be involved in calcification, we did observe differential expression of an L-type calcium channel, which is thought to regulate calcium ion transport into the calicoblastic epithelium [115]; however it was up-regulated in bases. Up-regulation of control of $\mathrm{pH}$ and carbonate concentrations in growing tips was indicated by overall increased expression of CA and a bicarbonate transport protein, SLC4A4. Other ion transport genes, including calcium transport, were up-regulated in both branch tips and bases.

Coral skeleton formation is believed to involve ECM, both as SOM and as a boundary region. In our results, galaxin-2, a number of proteins with similarity to $A$. millepora SOM [127] (mucin, hemicentin, polycystin-1, protocadherins and colla1), and ECM proteins with homologs involved in biomineralization in other species (ISMP-1, chondroadherin, uromodulin and collagen types I, II, XI, XXVII) were DE between tips and bases. These may be important candidate genes to investigate further as research continues into the effects of reduced oceanic $\mathrm{pH}$ on coral calcification.

In addition to the strong signature of DE developmental signaling genes and the numerous putative skeletal growth-related genes, we observed some differences between branch bases and tips for metabolic functions, response to environmental stimuli and stress and cnidarianspecific genes. Metabolic activity and translation were up-regulated in branch tips, supporting previous findings of increased respiration at distal regions of Acropora branches [40]. In this region where new tissue and polyps are being produced and mitotic rate is increased [40], it is consistent that we observed an increased signature of translation and production of mitochondrial respiratory proteins (ETC.). Interestingly, cytoskeletal genes were up-regulated in branch bases, which is unexpected but may be related to the production of gametes in this region. Some carbohydrate and lipid metabolic genes were DE by colony position; in particular, we speculate that DE lipid metabolic genes may be involved with gamete production and sphingolipid metabolism genes may be involved with regulating symbionts (see next section). Up-regulation of light and stress response genes was divided between tips and bases, though HSP70 was consistently up-regulated in bases. The DE light response genes, including $r d h \mathrm{~s}$ and melatonin receptors, may be involved in phototropic growth response, tentacle behavior and/or spawning. Cnidarian-specific genes involved in nematocyst production were consistently up-regulated in growing tips, and a majority of predicted proteins annotating to $N$. vectensis, which may represent taxonomically-restricted proteins, were also up-regulated in branch tips and may have a role in growth and calcification.

\section{Differences between $A$. cervicornis \& A. palmata}

The two coral species investigated, $A$. cervicornis and $A$. palmata, are sister species believed to have diverged in the Caribbean Sea approximately 3 million years ago [46]. While both species exhibit branching patterns, their morphologies are highly distinct from each other and they occupy different ecological niches. Despite these differences, these species are capable of sexual reproduction to produce F1 hybrids that display an intermediate phenotype known as $A$. prolifera [45]. RNA-seq results identified many differences in gene expression between these species that may be attributable to physiology, environment, and/or response to symbiont activity. To determine 
how these two species regulate the processes of growth and reproduction to achieve their distinct growth forms, we evaluated the 69 annotated transcripts that were DE both by colony position and by species, or that showed an interaction between the two factors (Figure 5).

Few of these candidate genes were associated but rather spanned a number of biological functions. Results suggest that differences in growth form between $A$. cervicornis and A. palmata involve Wnt, Notch, and possibly BMP signaling, regulation of bicarbonate transport by a sodium-driven chloride bicarbonate exchanger, and ECM proteins. Wnt and Notch genes DE for both factors were consistently up-regulated in tips, with three Wnt-related genes most highly expressed in A. cervicornis tips (cthrc1, apolipophorins, $\operatorname{lrp} 1 B$ ) and two in A. palmata tips ( $f z d 6$ and sox9). Cthrc, Lrp1 (a protein with similarities to Lrp1B) and Fzd6 are associated with repression of canonical Wnt signaling pathways $[63,66,70]$, while apolipophorins are associated with transport of Wnt and Hedgehog molecules [65] and Sox9 is a ß-catenin-interacting transcription factor known as a master regulator of cartilage development [69]. Due to its critical role in dictating polyp growth form, Wnt regulation has been proposed as a mechanism driving morphological differences among cnidarian species [165]. Our data suggest that activation/inhibition and transport of Wnt signaling are also important in colonial corals and may play a role in maintaining dominance of a single or few axial polyps in $A$. cervicornis relative to $A$. palmata. Though one Notch receptor gene, notch1, was up-regulated in $A$. cervicornis tips, and one tentative BMP signaling gene, $f_{s t l 4}$, was up-regulated in $A$. cervicornis bases, these pathways are not well characterized in cnidarians, so it is more difficult to speculate on their roles. Notch signaling, which is necessary for cell fate specification, neurogenesis and nematocyte differentiation in cnidarians, may be up-regulated in A. cervicornis tips because of the faster linear extension growth rate in this species.

In addition to developmental signaling pathways, some genes that may be more directly related to skeletal growth were DE for both factors. Although A. cervicornis has a slightly faster rate of linear branch extension than A. palmata, that growth is typically driven by a single axial polyp, with a number of smaller radial polyps developing along the side of the branch. In contrast, in A. palmata, multiple fused axial-type polyps lead branch extension simultaneously. One gene that may be responsible for the robust skeleton of $A$. palmata is the bicarbonate transport protein SLC4A10, which was up-regulated in $A$. palmata tips. Interestingly, a calcium transport gene, calcium entry channel, was up-regulated in $A$. cervicornis bases, but this gene may be involved in other calcium-signaling related functions such as light-response and spawning [95]. A number of ECM genes showed species-specific expression, including three genes related to known A. millepora SOM proteins, hemicentin, protocadherin Fat 2 and a cephalotoxin (from $S$. esculenta). Other ECM genes with a potential role in morphological differences between species include collagen interacting proteins (cthrc1 and loxl2), and a C-type lectin involved in biomineralization of barnacles, lectin $B R A-3$. It is not understood how these ECM proteins function in corals, but they may serve as candidates for further research.

Species-specific expression of the sphingolipid biosynthesis gene DEGS2, which was up-regulated in $A$. cervicornis bases and down-regulated in $A$. palmata bases, may be related the regulation of the sphingosine rheostat, a regulatory mechanism that balances signaling sphingolipids involved in cell fate and immunity, and which is suspected to facilitate coral-symbiont interactions [146]. Regulation of sphingolipids may therefore differ between species due to environmental differences that affect symbiont activity, such as temperature and light exposure. Light and heat response genes were consistently up-regulated in A. palmata, probably due to the greater light intensity of the reef crest environment. Two lightresponse genes, rdh8 and crumbs homolog 1, and the HSP70 co-chaperone sacsin were up-regulated in $A$. palmata bases. Up-regulation of sacsin in A. palmata branch bases may be attributable to increased concentration of ROS in symbiont-rich regions of branches. A GFPlike protein up-regulated in A. palmata tips is also possibly involved in photoprotection of coral tissues [156,157].

These annotated DE genes, however, do not reflect the full extent of gene expression differences between species since many genes were found to be most similar to $N$. vectensis predicted proteins, which may be cnidarianspecific, and approximately 250 transcripts DE for both factors were not annotated. Further research is needed to identify the precise location and interactions of these candidate genes and to characterize their roles in coral growth. Additionally, a number of transcripts were DE for both factors, but did not meet our criterion of a 2-fold change magnitude of expression for one or both factors. Some of these, such as transcripts of CA2 (up in tips of A. cervicornis), calmodulin (up in tips of $A$. palmata), chordin (up in bases of $A$. palmata) were considered as $\mathrm{DE}$ for colony position, but may also be involved in differences between species.

The two species investigated are closely related enough to permit hybridization [45], but display distinct morphological characteristics and occupy different habitats: $A$. palmata is found in the high-energy reef crest and $A$. cervicornis inhabits the lower energy fore- and back-reef. As expected, we found that transcriptomes for these species exhibit large differences in gene expression, many of which are certainly due to differences in environmental 
factors, but some of which likely indicate differences in genetic regulation of growth form. Though studies on the role of gene expression in species evolution in corals are lacking, more is known in bilaterian systems in which the roles of developmental patterning genes such as Hox, Wnt, BMP and Hedgehog have been more widely explored. Studies in model systems indicate that changes in location, magnitude and timing of expression of functionally conserved genes, particularly during development, are responsible for morphological differences between species [166]. While colonial cnidarians differ from these other groups of organisms in that they represent a more ancestral lineage, are comprised of a coordinated group of multiple modular polyps, and display indeterminate growth, our results suggest that similar genetic signaling pathways are associated with their divergent morphologies. Furthermore, the genetic regulation of biomineralization may involve genes similar to those involved in constructing the mineralized structures in higher animals. Vertebrate species with adaptive radiations of bony and cartilaginous features, such as the beaks of finches and jaws of fish, exhibit gene expression patterns and rates of genetic evolution implicating similar genetic pathways (Wnt, BMP, calmodulin) in the development of divergent morphologies that allow adaptation to varied habitats and food sources $[82,99,100,167,168]$. Additional research into the gene expression of candidate genes in the hybrid A. prolifera and in the highly diverse Pacific Acropora corals can provide additional insights into the role of gene expression the evolution of their growth forms.

\section{Conclusions}

Our RNA-seq results demonstrate that there are large differences in gene expression representing a strong DOL between polyps in the growing tips of branches compared to branch bases for both Caribbean Acropora. The number of transcripts differentially regulated by position within individual colonies $(n=2215)$ is of the same magnitude as differences between the two species $(n=2288)$. Genes showing differing levels of expression between branch tips and bases point to roles for classical development signaling pathways (Wnt, Notch and BMP) in branch extension and polyp development. Differential expression of CA, ion transport, ECM and putative SOM genes, indicate candidates that may be involved in the active control of skeleton growth by reef-building corals. A small number of genes were identified as DE both by colony position and species, pointing to genes that may play a role in regulating the different growth morphologies between these species.

\section{Methods}

\section{Sample collection \& RNA extraction}

Acropora cervicornis and A. palmata samples were collected in August 2009 from Crawl Cay, Bocas del Toro,
Panama. Paired apical tip (top $2 \mathrm{~cm}$ of branch) and base $(25-30 \mathrm{~cm}$ from the branch tip in A. cervicornis and $>10 \mathrm{~cm}$ from the branch tip in A. palmata) samples were collected for four colonies of $A$. cervicornis and three colonies of $A$. palmata. A cervicornis samples were collected from colonies at least $10 \mathrm{~m}$. apart at 5-6 m. depth, and A. palmata samples were collected from colonies 4-5 m. apart at 1-2 m. depth. Samples were flash frozen, placed in TRI Reagent (Molecular Research Center, Inc., Cincinnati, $\mathrm{OH}$ ) and stored at $-80^{\circ} \mathrm{C}$. Total RNA extraction was conducted using the TRI Reagent manufacturer's protocol with an additional 75\% ethanol wash step. Total RNA quality was assessed using Agilent Bioanalyzer 2100 RNA Pico Chips, and only extractions with clear distinct $18 \mathrm{~S}$ and $28 \mathrm{~S}$ ribosomal RNA peaks were used (RIN 5.3-8.3).

\section{Illumina RNA-seq library preparation, annotation and read mapping}

RNA-seq library preparation, read processing, transcriptome assembly and annotation were performed as described in Libro et al. [50]. The combined A. cervicornis/A. palmata de novo transcriptome that we used as a reference transcriptome is justified based on the less than $2 \%$ divergence in nucleotide composition between species for both mitochondrial and nuclear sequences [45]. Because galaxin and SCRiP genes may be important in coral calcification and development, we performed additional BLAST for multiple galaxin proteins (UniProt: D9IQ16, D9IQ17, D9IQ18, B8UU51, Q8I6S1, A8C9K2) and SCRiP nucleotide (GenBank: FJ842102-FJ842109, EU659816, BK006534-BK006538) sequences obtained from NCBI against queries for the full reference transcriptome. RNA-seq quantification of gene expression was conducted in CLC Genomics Workbench (CLC bio, Aarhus, Denmark) using local alignments, including nonspecific mappings across multiple contigs via random assignment. Default parameters were changed by lowering the length fraction to 0.4 and increasing the similarity to 0.9 to account for potential transcriptome fragmentation resulting from the short length $(36 \mathrm{bp})$ of our reads.

\section{Statistical analysis of differential expression}

To determine whether sample groups shared similar expression profiles, clustering of samples using nMDS and the Bray-Curtis similarity index were conducted in Primer v6 [169] using coral-only count data for transcripts with greater than 100 total normalized counts. Count data were normalized by library size using the DESeq package [170] in R ( $R$ Development Core Team, 2012). Permutational multivariate analysis of variance (PERMANOVA) [171] was conducted using Bray-Curtis similarity with permutation of residuals under a reduced model in Primer v6 to test the effect of the two random independent variables, species and colony position, as well as their interaction. A 
significant interaction indicates that the level of expression for one factor is dependent on the level of the other factor.

DE genes were identified using a two-factor negative binomial GLM test implemented using DESeq in R. This tests the effect of two independent factors, species (i.e. A. cervicornis vs. A. palmata) and colony position (i.e. branch base vs. branch tip) on the dependent variable (gene expression); the interaction between factors was also tested. Transcripts expressed at normalized counts less than 100 (sum for all 14 samples) were excluded from the analyses to prevent bias (i.e. genes expressed at a low concentration for which a small absolute change in expression would appear to be a large fold change). Transcripts with greater standard deviation than mean within any sample group (e.g. A. cervicornis tips) were also excluded (after [172]). An adjusted p-value $<0.05$ was used to evaluate significance [173]. We further narrowed our list of important significant DE genes by applying a threshold of 2 -fold (i.e. $\mid \log _{2}$-fold change $>1$ ) difference in gene expression, except for transcripts with a significant interaction effect. "Up-regulated" indicates a higher expression in the stated treatment, e.g. up-regulated in tips indicates higher expression in tips than in bases. Heat maps of selected genes were created using logtransformed normalized count data in GENE-E [174].

\section{Functional genetic pathway analysis}

GO terms were obtained from the GO database [175] for transcripts annotated with UniProt protein IDs (BLAST e-value $<10^{-5}$ ). Functional GO categories (for Biological Process) were further identified for DE genes using ErmineJ v. 3.0 [176], which classifies genes by GO category, identifies categories with many 'multifunctional' genes (which may be involved in many processes other than that specified by the current GO term), and determines if a category is 'enriched' for DE genes. The depth of GO annotation varied among transcripts; therefore, for functional definitions described in the results we conducted additional classification of genes based on UniProt annotations and a review of the literature.

For the DE Wnt genes, an additional BLAST (blastx) was conducted against the NCBI non-redundant protein sequence database to identify the closest cnidarian homo$\log$ to more precisely describe the putative functions of these genes.

\section{Availability of supporting data}

The reference transcriptome sequences are available on BioProject [accession number PRJNA222758, http://www. ncbi.nlm.nih.gov/bioproject/?term=PRJNA222758]. Annotations of the coral reference transcriptome (DOI:10.6070/ H4NZ85NM) and raw read count data (DOI:10.6070/ H4J67DX6) are available on LabArchives.com.

\section{Additional files}

Additional file 1: Average and standard error of RNA-seq library sizes by sample type.

Additional file 2: Data set of annotated (UniProt/Swiss-Prot e-val

$<10^{-10}$ ) coral transcripts. Includes adjusted $P$ and $\log _{2}$ (fold change) values, and putative functions of genes discussed in the manuscript. * Indicates annotation from GenBank.

\section{Abbreviations}

BMP: Bone morphogenetic protein; CA: Carbonic anhydrase; DE: Differentially expressed; DOL: Division of labor; ECM: Extra-cellular matrix; GO: Gene ontology; HSP: Heat shock protein; nMDS: Non-metric multidimensional scaling; NOWA: Nematocyst outer wall antigen; rdh: Retinol dehydrogenase; SCRiP: Small cysteine-rich proteins; SOM: Skeletal organic matrix.

\section{Competing interests}

The authors declare that they have no competing interests.

\section{Authors' contributions}

EMH conceived, designed and performed the experiments, analyzed the data and wrote the manuscript. SW conceived and designed the experiments, contributed reagents/materials/analysis tools and wrote the manuscript. STK performed bioinformatic analyses. All authors read and approved the final manuscript.

\section{Acknowledgements}

The authors would like to thank S. Libro for assistance with fieldwork and data analysis, L. Geyer and the Smithsonian Tropical Research Institute for field and logistical support, and E. Gladfelter, L. Kaufman, R. Bilgin and two anonymous reviewers for comments on the manuscript. Research was funded by NSF grant NSF-OCE 0751666 to SW and a Northeastern University Excellence Fellowship to EMH. Collection permits were provided by Autoridad Nacional del Ambiente (ANAM; permit no. SC/A-16-09).

Received: 23 June 2014 Accepted: 11 December 2014

Published: 17 December 2014

\section{References}

1. Mackie GO: From aggregates to integrates: physiological aspects of modularity in colonial animals. Phil Trans R SOC B 1986, 313:175-196.

2. Pearse $V B$, Muscatine $L$ : Role of symbiotic algae (zooxanthellae) in coral calcification. Biol Bull 1971, 141:350-363.

3. Cartwright P: The development and evolution of hydrozoan polyp and colony form. Hydrobiologia 2004, 530:309-317.

4. Siebert S, Robinson MD, Tintori SC, Goetz F, Helm RR, Smith SA, Shaner N, Haddock SHD, Dunn CW: Differential gene expression in the siphonophore Nanomia bijuga (Cnidaria) assessed with multiple next-generation sequencing workflows. PLOS One 2011, 6:e22953.

5. Gladfelter EH: Skeletal development in Acropora cervicornis: I. Patterns of calcium carbonate accretion in the axial corallite. Coral Reefs 1982, 1:45-51.

6. Rinkevich B: The branching coral Stylophora pistillata: contribution of genetics in shaping colony landscape. Isr J Zool 2002, 48:71-82.

7. Shaish L, Abelson A, Rinkevich B: How plastic can phenotypic plasticity be? The branching coral Stylophora pistillata as a model system. PLoS One 2007, 2:e644.

8. Todd PA: Morphological plasticity in scleractinian corals. Biol Rev 2008, 83:315-337.

9. Chiori R, Jager M, Denker E, Wincker P, Da Silva C, Le Guyader H, Manuel M, Quéinnec E: Are Hox genes ancestrally involved in axial patterning? evidence from the hydrozoan Clytia hemisphaerica (Cnidaria). PLoS One 2009, 4:e4231.

10. Matus DQ, Magie C, Pang K, Martindale MQ, Thomsen GH: The Hedgehog gene family of the cnidarian, Nematostella vectensis, and implications for understanding metazoan Hedgehog pathway evolution. Dev Biol 2008, 313:501-518.

11. Guder C, Philipp I, Lengfeld T, Watanabe H, Hobmayer B, Holstein TW: The Wnt code: cnidarians signal the way. Oncogene 2006, 25:7450-7460.

12. Kusserow A, Pang K, Sturm C, Hrouda M, Lentfer J, Schmidt H, Technau U, Haeseler von A, Hobmayer B, Martindale MQ, Holstein TW: Unexpected 
complexity of the Wnt gene family in a sea anemone. Nature 2005, 433:156-160.

13. Lee PN, Pang K, Matus DQ, Martindale MQ: A WNT of things to come: evolution of Wnt signaling and polarity in cnidarians. Semin Cell Dev Biol 2006, 17:157-167.

14. Samuel G, Miller D, Saint R: Conservation of a DPP/BMP signaling pathway in the nonbilateral cnidarian Acropora millepora. Evol Dev 2001, 3:241-250.

15. Zoccola D, Moya A, Béranger GE, Tambutté E, Allemand D, Carle GF, Tambutté S: Specific expression of BMP2/4 ortholog in biomineralizing tissues of corals and action on mouse BMP receptor. Mar Biotechnol 2009, 11:260-269.

16. Käsbauer T, Towb P, Alexandrova O, David CN, Dall'Armi E, Staudigl A, Stiening B, Böttger A: The Notch signaling pathway in the cnidarian Hydra. Dev Biol 2007, 303:376-390.

17. Marlow $H$, Roettinger $E$, Boekhout M, Martindale MQ: Functional roles of Notch signaling in the cnidarian Nematostella vectensis. Dev Biol 2012, 362:295-308.

18. Ball EE, Hayward DC, Saint R, Miller DJ: A simple plan — cnidarians and the origins of developmental mechanisms. Nat Rev Genet 2004, 5:567-577.

19. Martindale MQ: The evolution of metazoan axial properties. Nat Rev Genet 2005, 6:917-927.

20. Meyer E, Aglyamova GV, Wang S, Buchanan-Carter J, Abrego D, Colbourne JK, Willis BL, Matz MV: Sequencing and de novo analysis of a coral larval transcriptome using 454 GSFIx. BMC Genomics 2009, 10:219.

21. Steele R: Developmental signaling in Hydra: what does it take to build a "simple" animal? Dev Biol 2002, 248:199-219.

22. Steele RE, David CN, Technau U: A genomic view of 500 million years of cnidarian evolution. Trends Genet 2011, 27:7-13.

23. Bode HR: The role of Hox genes in axial patterning in Hydra. Integr Comp Biol 2001, 41:621-628.

24. Broun M, Gee L, Reinhardt B, Bode HR: Formation of the head organizer in hydra involves the canonical Wnt pathway. Development 2005, 132:2907-2916.

25. Müller WA, Teo R, Frank U: Totipotent migratory stem cells in a hydroid. Dev Biol 2004, 275:215-224

26. Hobmayer B, Rentzsch F, Kuhn K, Happel CM, Laue von CC, Snyder P, Rothbächer U, Holstein TW, Laue Von CC, Snyder P, Rothbächer U, Holstein TW: WNT signalling molecules act in axis formation in the diploblastic metazoan Hydra. Nature 2000, 407:186-189.

27. Plickert G, Jacoby $V$, Frank U, Müller WA, Mokady O: Wnt signaling in hydroid development: formation of the primary body axis in embryogenesis and its subsequent patterning. Dev Bio/ 2006, 298:368-378.

28. Duffy DJ, Plickert G, Kuenzel T, Tilmann W, Frank U: Wnt signaling promotes oral but suppresses aboral structures in Hydractinia metamorphosis and regeneration. Development 2010, 137:3057-3066.

29. Wikramanayake AH, Hong M, Lee PN, Pang K, Byrum CA, Bince JM, Xu R Martindale MQ: An ancient role for nuclear $ß$-catenin in the evolution of axial polarity and germ layer segregation. Nature 2003, 426:446-450

30. de Jong DM, Hislop NR, Hayward DC, Reece-Hoyes JS, Pontynen PC, Ball EE, Miller DJ: Components of both major axial patterning systems of the Bilateria are differentially expressed along the primary axis of a "radiate" animal, the anthozoan cnidarian Acropora millepora. Dev Biol 2006, 298:632-643.

31. Hayward DC, Catmull J, Reece-Hoyes JS, Berghammer H, Dodd H, Hann SJ, Miller DJ, Ball EE: Gene structure and larval expression of cnox-2Am from the coral Acropora millepora. Dev Genes Evol 2001, 211:10-19.

32. Cartwright P, Bowsher J, Buss LW: Expression of a Hox gene, Cnox-2, and the division of labor in a colonial hydroid. Proc Natl Acad Sci U S A 1999, 96:2183-2186

33. Cartwright $P$, Schierwater B, Buss LW: Expression of a Gsx parahox gene, Cnox-2, in colony ontogeny in Hydractinia (Cnidaria: Hydrozoa). J Exp Zool Part A 2006, 306B:460-469.

34. Grasso LC, Maindonald J, Rudd S, Hayward DC, Saint R, Miller DJ, Ball EE: Microarray analysis identifies candidate genes for key roles in coral development. BMC Genomics 2008, 9:540.

35. Grasso LC, Negri AP, Forêt S, Saint R, Hayward DC, Miller DJ, Ball EE: The biology of coral metamorphosis: molecular responses of larvae to inducers of settlement and metamorphosis. Dev Biol 2011, 353:411-419.

36. Oliver JK: Intra-colony variation in the growth of Acropora formosa: extension rates and skeletal structure of white (zooxanthellae-free) and brown-tipped branches. Coral Reefs 1984, 3:139-147.
37. Goreau TF: The physiology of skeleton formation in corals. I. A method for measuring the rate of calcium deposition by corals under different conditions. Biol Bull 1959, 116:59-75.

38. Goreau TF: Calcium carbonate deposition by coralline algae and corals in relation to their roles as reef-builders. Ann N Y Acad Sci 1963, 109:127-167.

39. Goreau TF, Goreau N: The physiology of skeleton formation in corals. II. Calcium deposition by hermatypic corals under various conditions in the reef. Biol Bull 1959, 117:239-250.

40. Gladfelter EH, Michel G, Sanfelici A: Metabolic gradients along a branch of the reef coral Acropora palmata. B Mar Sci 1989, 44:1166-1173.

41. Oliver JK: Aspects of skeletal growth in the Indo-Pacific staghorn coral Acropora formosa. PhD thesis. James Cook University, Marine Biology Department; 1987

42. Szmant AM: Reproductive ecology of Caribbean reef corals. Coral Reefs 1986, 5:43-53.

43. Wallace $\mathrm{C}$ : Reproduction, recruitment and fragmentation in nine sympatric species of the coral genus Acropora. Mar Biol 1985, 88:217-233.

44. Bay LK, Nielsen HB, Jarmer H, Seneca F, van Oppen MJH: Transcriptomic variation in a coral reveals pathways of clonal organisation. Mar Genom 2009, 2:119-125

45. Vollmer SV, Palumbi SR: Hybridization and the evolution of reef coral diversity. Science 2002, 296:2023-2025.

46. McNeill DF, Budd AF, Borne PF: Earlier (late Pliocene) first appearance of the Caribbean reef-building coral Acropora palmata: Stratigraphic and evolutionary implications. Geol 1997, 25:891.

47. Polato NR, Vera JC, Baums IB: Gene discovery in the threatened elkhorn coral: 454 sequencing of the Acropora palmata transcriptome. PLoS One 2011, 6:e28634.

48. Meyer E, Aglyamova GV, Matz MV: Profiling gene expression responses of coral larvae (Acropora millepora) to elevated temperature and settlement inducers using a novel RNA-Seq procedure. Mol Ecol 2011, 20:3599-3616.

49. Moya A, Huisman L, Ball EE, Hayward DC, Grasso LC, Chua CM, Woo HN, Gattuso J-P, Forêt S, Miller DJ: Whole transcriptome analysis of the coral Acropora millepora reveals complex responses to $\mathrm{CO}_{2}$-driven acidification during the initiation of calcification. Mol Ecol 2012, 21:2440-2454.

50. Libro S, Kaluziak ST, Vollmer SV: RNA-seq profiles of immune related genes in the staghorn coral Acropora cervicornis infected with White Band Disease. PLoS One 2013, 8:e81821

51. Cohen AL, McConnaughey TA: Geochemical perspectives on coral mineralization. Rev Mineral Geochem 2003, 54:151-187.

52. Technau U, Steele RE: Evolutionary crossroads in developmental biology: Cnidaria. Development 2011, 138:1447-1458

53. Guder C: An ancient Wnt-Dickkopf antagonism in Hydra. Development 2006, 133:901-911.

54. Trevino M, Stefanik DJ, Rodriguez R, Harmon S, Burton PM: Induction of canonical Wnt signaling by alsterpaullone is sufficient for oral tissue fate during regeneration and embryogenesis in Nematostella vectensis. Dev Dyn 2011, 240:2673-2679.

55. Momose T, Houliston E: Two oppositely localised frizzled RNAs as axis determinants in a cnidarian embryo. PLoS Biol 2007, 5:e70.

56. Philipp I, Aufschnaiter R, Özbek S, Pontasch $S$, Jenewein $M$, Watanabe $H$, Rentzsch F, Holstein TW, Hobmayer B: Wnt/ß-Catenin and noncanonical Wnt signaling interact in tissue evagination in the simple eumetazoan Hydra. Proc Natl Acad Sci U S A 2009, 106:4290-4295.

57. Lengfeld T, Watanabe H, Simakov O, Lindgens D, Gee L, Law L, Schmidt HA, Özbek S, Bode H, Holstein TW: Multiple Wnts are involved in Hydra organizer formation and regeneration. Dev Biol 2009, 330:186-199.

58. Onai T, Akira T, Setiamarga DHE, Holland LZ: Essential role of Dkk3 for head formation by inhibiting Wnt/B-catenin and Nodal/Vg1 signaling pathways in the basal chordate amphioxus. Evol Dev 2012, 14:338-350.

59. Nakamura REl, Hackam AS: Analysis of Dickkopf3 interactions with Wnt signaling receptors. Growth Factors 2010, 28:232-242.

60. Mallarino R, Grant PR, Grant BR, Herrel A, Kuo WP, Abzhanov A: Two developmental modules establish 3D beak-shape variation in Darwin's finches. Proc Natl Acad Sci U S A 2011, 108:4057-4062.

61. Fedders H, Augustin R, Bosch TCG: A Dickkopf-3-related gene is expressed in differentiating nematocytes in the basal metazoan Hydra. Dev Genes Evol 2004, 214:72-80

62. Williams BO, Insogna KL: Where Wnts went: the exploding field of Lrp5 and Lrp6 signaling in bone. J Bone Miner Res 2009, 24:171-178. 
63. Yamamoto S, Nishimura O, Misaki K, Nishita M, Minami Y, Yonemura S, Tarui $\mathrm{H}$, Sasaki $\mathrm{H}$ : Cthrc1 selectively activates the planar cell polarity pathway of Wnt signaling by stabilizing the Wnt-receptor complex. Dev Cell 2008 $15: 23-36$

64. Pyagay $P$, Heroult M, Wang Q, Lehnert W, Belden J, Liaw L, Friesel RE, Lindner V: Collagen triple helix repeat containing 1, a novel secreted protein in injured and diseased arteries, inhibits collagen expression and promotes cell migration. Circ Res 2005, 96:261-268.

65. Panakova D, Sprong H, Marois E, Thiele C, Eaton S: Lipoprotein particles are required for Hedgehog and Wingless signalling. Nature 2005, 435:58-65.

66. Golan T, Yaniv A, Bafico A, Liu G, Gazit A: The human frizzled 6 (HFz6) acts as a negative regulator of the canonical Wnt- $ß$-catenin signaling cascade. J Biol Chem 2004, 279:14879-14888.

67. Cui C-Y, Klar J, Georgii-Heming P, Fröjmark A-S, Baig SM, Schlessinger D, Dahl N: Frizzled6 deficiency disrupts the differentiation process of nail development. J Investig Dermatol 2013, 133:1990-1997.

68. Yano F, Kugimiya F, Ohba S, Ikeda T, Chikuda H, Ogasawara T, Ogata N, Takato T, Nakamura K, Kawaguchi H, Chung U-l: The canonical Wnt signaling pathway promotes chondrocyte differentiation in a Sox9-dependent manner. Biochem Biophys Res Comm 2005, 333:1300-1308.

69. Akiyama H, Lyons JP, Mori-Akiyama Y, Yang X, Zhang R, Zhang Z, Deng JM Taketo MM, Nakamura T, Behringer RR, McCrea PD, de Crombrugghe B: Interactions between Sox 9 and $ß$-catenin control chondrocyte differentiation. Gene Dev 2004, 18:1072-1087.

70. Zilberberg A, Yaniv A, Gazit A: The low density lipoprotein receptor-1, LRP1, interacts with the human frizzled-1 (HFz1) and down-regulates the canonical Wnt signaling pathway. J Biol Chem 2004, 279:17535-17542.

71. Koch U, Lehal R, Radtke F: Stem cells living with a Notch. Development 2013, 140:689-704

72. Münder S, Käsbauer T, Prexl A, Aufschnaiter R, Zhang X, Towb P, Böttger A Notch signalling defines critical boundary during budding in Hydra. Dev Biol 2010, 344:331-345.

73. Collu GM, Hidalgo-Sastre A, Acar A, Bayston L, Gildea C, Leverentz MK, Mills CG, Owens TW, Meurette O, Dorey K, Brennan K: Dishevelled limits Notch signalling through inhibition of CSL. Development 2012, 139:4405-4415.

74. Lin GL, Hankenson KD: Integration of BMP, Wnt, and notch signaling pathways in osteoblast differentiation. J Cell Biochem 2011, 112:3491-3501.

75. Matus DQ, Thomsen GH, Martindale MQ: Dorso/ventral genes are asymmetrically expressed and involved in germ-layer demarcation during cnidarian gastrulation. Curr Biol 2006, 16:499-505.

76. lemura S, Yamamoto TS, Takagi C, Uchiyama H, Natsume T, Shimasaki S, Sugino $\mathrm{H}$, Ueno N: Direct binding of follistatin to a complex of bonemorphogenetic protein and its receptor inhibits ventral and epidermal cell fates in early Xenopus embryo. Proc Natl Acad Sci U S A 1998, 95:9337-9342.

77. Holley SA, Jackson PD, Sasai Y, Lu B, De Robertis EM, Hoffmann FM, Ferguson EL: A conserved system for dorsal-ventral patterning in insects and vertebrates involving sog and chordin. Nature 1995, 376:249-253.

78. Niehrs C: On growth and form: a Cartesian coordinate system of Wnt and BMP signaling specifies bilaterian body axes. Development 2010, 137:845-857.

79. Hayward DC, Samuel G, Pontynen PC, Catmull J, Saint R, Miller DJ, Ball EE: Localized expression of a dpp/BMP2/4 ortholog in a coral embryo. Proc Natl Acad Sci U S A 2002, 99:8106-8111.

80. Rentzsch F, Anton R, Saina M, Hammerschmidt M, Holstein TW, Technau U: Asymmetric expression of the BMP antagonists chordin and gremlin in the sea anemone Nematostella vectensis: Implications for the evolution of axial patterning. Dev Biol 2006, 296:375-387.

81. Saina M, Genikhovich G, Renfer E, Technau U: BMPs and chordin regulate patterning of the directive axis in a sea anemone. Proc Natl Acad SC U S A 2009, 106:18592-18597.

82. Parsons KJ, Albertson RC: Roles for Bmp4 and CaM1 in shaping the jaw: Evo-Devo and beyond. Annu Rev Genet 2009, 43:369-388.

83. Daluiski A, Engstrand T, Bahamonde ME, Gamer LW, Agius E, Stevenson SL, Cox K, Rosen V, Lyons KM: Bone morphogenetic protein-3 is a negative regulator of bone density. Nat Genet 2001, 27:84-88.

84. Hino J, Nishimatsu S-I, Nagai T, Matsuo H, Kangawa K, Nohno T: Coordination of BMP-3b and cerberus is required for head formation of Xenopus embryos. Dev Biol 2003, 260:138-157.

85. Hino J, Kangawa K, Matsuo H, Nohno T, Nishimatsu S: Bone morphogenetic protein-3 family members and their biological functions. Front Biosci 2004, 9:1520-1529
86. Gauchat D, Kreger $S$, Holstein T, Galliot B: prdl-a, a gene marker for hydra apical differentiation related to triploblastic paired-like head-specific genes. Development 1998, 125:1637-1645.

87. Broun M, Sokol S, Bode HR: Cngsc, a homologue of goosecoid, participates in the patterning of the head, and is expressed in the organizer region of Hydra. Development 1999, 126:5245-5254.

88. Srivastava M, Larroux C, Lu DR, Mohanty K, Chapman J, Degnan B, Rokhsar DS: Early evolution of the LIM homeobox gene family. BMC Biol 2010, 8:4.

89. Sinigaglia $C$, Busengdal $H$, Leclère $L$, Technau $U$, Rentzsch F: The bilaterian head patterning gene six $3 / 6$ controls aboral domain development in a cnidarian. PLOS Biol 2013, 11:e1001488.

90. Martinez DE, Dirksen ML, Bode PM, Jamrich M, Steele RE, Bode HR: Budhead, a fork head/HNF-3 homologue, is expressed during axis formation and head specification in Hydra. Dev Biol 1997, 192:523-536.

91. Magie CR, Pang K, Martindale MQ: Genomic inventory and expression of Sox and Fox genes in the cnidarian Nematostella vectensis. Dev Genes Evol 2005, 215:618-630.

92. Benayoun BA, Caburet S, Veitia RA: Forkhead transcription factors: key players in health and disease. Trends Genet 2011, 27:224-232.

93. Roberts RB, Hu Y, Albertson RC, Kocher TD: Craniofacial divergence and ongoing adaptation via the hedgehog pathway. Proc Natl Acad Sci U S A 2011, 108:13194-13199.

94. Case R, Eisner D, Gurney A, Jones O, Muallem S, Verkhratsky A: Evolution of calcium homeostasis: from birth of the first cell to an omnipresent signalling system. Cell Calcium 2007, 42:345-350.

95. Hilton JD, Brady AK, Spaho SA, Vize PD: Photoreception and signal transduction in corals: proteomic and behavioral evidence for cytoplasmic calcium as a mediator of light responsivity. Biol Bull 2012, 223:291-299.

96. Russell TJ, Watson GM: Evidence for intracellular stores of calcium ions involved in regulating nematocyst discharge. J Exp Zool 1995, 273:175-185.

97. Reyes-Bermudez A, DeSalvo MK, Voolstra CR, Sunegawa S, Szmant AM, Iglesias-Prieto R, Medina M: Gene expression microarray analysis encompassing metamorphosis and the onset of calcification in the scleractinian coral Montastraea faveolata. Mar Genomics 2009, 2:149-159.

98. Dunlap WC, Starcevic A, Baranasic D, Diminic J, Zucko J, Gacesa R, van Oppen MJH, Hranueli D, Cullum J, Long PF: KEGG orthology-based annotation of the predicted proteome of Acropora digitifera: ZoophyteBase - an open access and searchable database of a coral genome. BMC Genomics 2013, 14:1

99. Mallarino R, Campàs O, Fritz JA, Burns KJ, Weeks OG, Brenner MP, Abzhanov A: Closely related bird species demonstrate flexibility between beak morphology and underlying developmental programs. Proc Natl Acad Sci US A 2012, 109:16222-16227.

100. Abzhanov A, Kuo WP, Hartmann C, Grant BR, Grant PR, Tabin CJ: The calmodulin pathway and evolution of elongated beak morphology in Darwin's finches. Nature 2006, 442:563-567.

101. Gladfelter EH: Skeletal development in Acropora palmata (Lamarck 1816): a scanning electron microscope (SEM) comparison demonstrating similar mechanisms of skeletal extension in axial versus encrusting growth. Coral Reefs 2007, 26:883-892.

102. Gladfelter EH: Skeletal development in Acropora cervicornis II: Diel patterns of calcium carbonate accretion. Coral Reefs 1983, 2:91-100.

103. Gladfelter EH, Monahan R, Gladfelter WB: Growth rates of five reef-building corals in the northeastern Caribbean. B Mar Sci 1978, 28:728-734.

104. Bak RPM: The growth of coral colonies and the importance of crustose coralline algae and burrowing sponges in relation with carbonate accumulation. Neth J Sea Res 1976, 10:285.

105. Shinn EA: Coral growth-rate, an environmental indicator. J Paleontol 1966, 40:233-240.

106. Schuhmacher H, Plewka M: The Adaptive Significance of Mechanical Properties Versus Morphological Adjustments in Skeletons of Acropora palmata and Acropora cervicornis (Cnidaria, Scleractinia). In Proceedings of the Fourth International Coral Reef Symposium, Volume 2. Manila: 1981:121-128.

107. Tambutté $S$, Holcomb M, Ferrier-Pagès $C$, Reynaud S, Tambutté E, Zoccola D, Allemand D: Coral biomineralization: from the gene to the environment. J Exp Mar Biol Ecol 2011, 408:58-78.

108. Venn AA, Tambutté E, Lotto S, Zoccola D, Allemand D, Tambutté S: Imaging intracellular $\mathrm{pH}$ in a reef coral and symbiotic anemone. Proc Natl Acad SCi US A 2009, 106:16574-16579. 
109. Al-Horani FA, Al-Moghrabi SM, de Beer D: The mechanism of calcification and its relation to photosynthesis and respiration in the scleractinian coral Galaxea fascicularis. Mar Biol 2003, 142:419-426.

110. Chalker BE: Calcium transport during skeletogenesis in hermatypic corals. Comp Biochem Physiol A Comp Physiol 1976, 54:455-459.

111. Marshall AT, Clode PL, Russell R, Prince K, Stern R: Electron and ion microprobe analysis of calcium distribution and transport in coral tissues. J Exp Biol 2007, 210:2453-2463.

112. Tambutté S, Tambutté E, Zoccola D, Caminiti N, Lotto S, Moya A, Allemand D, Adkins J: Characterization and role of carbonic anhydrase in the calcification process of the azooxanthellate coral Tubastrea aurea. Mar Biol 2006, 151:71-83.

113. Moya A, Tambutté S, Bertucci A, Tambutté E, Lotto S, Vullo D, Supuran CT, Allemand D, Zoccola D: Carbonic anhydrase in the scleractinian coral Stylophora pistillata: characterization, localization, and role in biomineralization. J Biol Chem 2008, 283:25475-25484

114. Allemand D, Ferrier-Pagès C, Furla P, Houlbrèque F, Puverel S, Reynaud S, Tambutté E, Tambutté S, Zoccola D: Biomineralisation in reef-building corals: from molecular mechanisms to environmental control. Comptes Rendus Palevol 2004, 3:453-467.

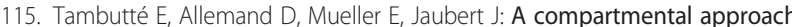
to the mechanism of calcification in hermatypic corals. J Exp Biol 1996 199:1029-1041.

116. Zoccola D, Tambutté E, Senegas-Balas F, Michiels J-F, Failla J-P, Jaubert J, Allemand D: Cloning of a calcium channel a1 subunit from the reef-building coral, Stylophora pistillata. Gene 1999, 227:157-167.

117. Zoccola D, Tambutté E, Kulhanek E, Puverel S, Scimeca J-C, Allemand D, Tambutté S: Molecular cloning and localization of a PMCA P-type calcium ATPase from the coral Stylophora pistillata. BBA Biomembranes 2004, 1663:117-126.

118. Furla P, Allemand D, Orsenigo MN: Involvement of H(+)-ATPase and carbonic anhydrase in inorganic carbon uptake for endosymbiont photosynthesis. Am J Physiol Regul Integr Comp Physiol 2000, 278:R870-R881

119. Barnes DJ: Coral skeletons: an explanation of their growth and structure. Science 1970, 170:1305-1308.

120. Constantz BR: Coral skeleton construction: a physiochemically dominated process. Palaios 1986, 1:152-157.

121. Cuif J-P, Dauphin Y, Gautret P: Compositional diversity of soluble mineralizing matrices in some recent coral skeletons compared to fine-scale growth structures of fibres: discussion of consequences for biomineralization diagenesis. Int J Earth Sci 1999, 88:582-592.

122. Fukuda I, Ooki S, Fujita T, Murayama E, Nagasawa H, Isa Y, Watanabe T: Molecular cloning of a cDNA encoding a soluble protein in the coral exoskeleton. Biochem Biophys Res Comm 2003, 304:11-17.

123. Watanabe T: Molecular analyses of protein components of the organic matrix in the exoskeleton of two scleractinian coral species. Comp Biochem Phys B 2003, 136:767-774.

124. Puverel S, Tambutté E, Zoccola D, Domart-Coulon I, Bouchot A, Lotto S, Allemand D, Tambutté S: Antibodies against the organic matrix in scleractinians: a new tool to study coral biomineralization. Coral Reefs 2004, 24:149-156.

125. Puverel S, Tambutté E, Pereira-Mouriès L, Zoccola D, Allemand D, Tambutté S: Soluble organic matrix of two scleractinian corals: partial and comparative analysis. Comp Biochem Phys B 2005, 141:480-487.

126. Helman Y, Natale F, Sherrell RM, Lavigne M, Starovoytov V, Gorbunov MY, Falkowski PG: Extracellular matrix production and calcium carbonate precipitation by coral cells in vitro. Proc Natl Acad Sci U S A 2008, 105:54-58.

127. Ramos-Silva P, Kaandorp JA, Huisman L, Marie B, Zanella-Cleon I, Guichard N, Miller DJ, Marin F: The skeletal proteome of the coral Acropora millepora: the evolution of calcification by co-option and domain shuffling. Mol Biol Evol 2013, 30:2099-2112.

128. Sunagawa S, DeSalvo MK, Voolstra CR, Reyes-Bermudez A, Medina M: Identification and gene expression analysis of a taxonomically restricted cysteine-rich protein family in reef-building corals. PLoS One 2009, 4:e4865.

129. Puverel $S$, Houlbrèque F, Tambutté E, Zoccola D, Payan P, Caminiti N, Tambutté S, Allemand D: Evidence of low molecular weight components in the organic matrix of the reef building coral, Stylophora pistillata. Comp Biochem Phys A 2007, 147:850-856.

130. Wainwright SA: Skeletal organization in the coral, Pocillopora damicornis. Q J Microsc Sci 1963, 3:169-183.
131. Young SD: Calcification and synthesis of skeletal organic material in the coral, Pocillopora damicornis (L.)(Astrocoeniidae, Scleractinia). Comp Biochem Physiol A Comp Physiol 1973, 44:669-672.

132. Reyes-Bermudez A, Lin Z, Hayward DC, Miller DJ, Ball EE: Differential expression of three galaxin-related genes during settlement and metamorphosis in the scleractinian coral Acropora millepora. BMC Evol Biol 2009, 9:178.

133. Hayward DC, Hetherington S, Behm CA, Grasso LC, Forêt S, Miller DJ, Ball EE: Differential gene expression at coral settlement and metamorphosis - A subtractive hybridization study. PLoS One 2011, 6:e26411.

134. Siboni N, Abrego D, Motti CA, Tebben J, Harder T: Gene expression patterns during the early stages of chemically induced larval metamorphosis and settlement of the coral Acropora millepora. PLoS One 2014, 9:e91082.

135. Marin F, Corstjens P, de Gaulejac B, de Vrind-De JE, Westbroek P: Mucins and molluscan calcification. Molecular characterization of mucoperlin, a novel mucin-like protein from the nacreous shell layer of the fan mussel Pinna noblis (Bivalvia, Pteriomorphia). J Biol Chem 2000, 275:20667-20675.

136. Brown BE, Bythell JC: Perspectives on mucus secretion in reef corals. Mar Ecol Prog Ser 2005, 296:291-309.

137. Muscatine L, Tambutté E, Allemand D: Morphology of coral desmocytes, cells that anchor the calicoblastic epithelium to the skeleton. Coral Reefs 1997, 16:205-213.

138. Goldberg WM: Desmocytes in the calicoblastic epithelium of the stony coral Mycetophyllia reesi and their attachment to the skeleton. Tissue Cell 2001, 33:388-394

139. Marie B, Trinkler N, Zanella-Cleon I, Guichard N, Becchi M, Paillard C, Marin F: Proteomic identification of novel proteins from the calcifying shell matrix of the manila clam Venerupis philippinarum. Mar Biotechnol 2011, 13:955-962.

140. Ganot P, Moya A, Magnone V, Allemand D, Furla P, Sabourault C: Adaptations to endosymbiosis in a cnidarian-dinoflagellate association: differential gene expression and specific gene duplications. PLOS Genet 2011, 7:e1002187.

141. Muramoto K, Yako H, Murakami K, Odo S, Kamiya H: Inhibition of the growth of calcium carbonate crystals by multiple lectins in the coelomic fluid of the acorn barnacle Megabalanus rosa. Comp Biochem Phys B 1994, 107:401-409.

142. Matsubara $H$, Hayashi T, Ogawa T, Muramoto K, Jimbo M, Kamiya H: Modulating effect of acorn barnacle C-type lectins on the crystallization of calcium carbonate. Fisheries Sci 2008, 74:418-424.

143. Kamiya H, Jimbo M, Yako H, Muramoto K, Nakamura O, Kado R, Watanabe T: Participation of the C-type hemolymph lectin in mineralization of the acorn barnacle Megabalanus rosa. Mar Biol 2002, 140:1235-1240.

144. Kvennefors ECE, Leggat W, Hoegh-Guldberg O, Degnan BM, Barnes AC: An ancient and variable mannose-binding lectin from the coral Acropora millepora binds both pathogens and symbionts. Dev Comp Immunol 2008, 32:1582-1592

145. Wood-Charlson EM, Weis VM: The diversity of C-type lectins in the genome of a basal metazoan, Nematostella vectensis. Dev Comp Immunol 2009, 33:881-889.

146. Detournay $\mathrm{O}$, Weis VM: Role of the sphingosine rheostat in the regulation of cnidarian-dinoflagellate symbioses. Biol Bull 2011, 221:261-269.

147. Bachok Z, Mfilinge P, Tsuchiya M: Characterization of fatty acid composition in healthy and bleached corals from Okinawa, Japan. Coral Reefs 2006, 25:545-554

148. Arai I, Kato M, Heyward A, Ikeda Y, lizuka T, Maruyama T: Lipid composition of positively buoyant eggs of reef building corals. Coral Reefs 1993, 12:71-75.

149. Yu BP: Cellular defenses against damage from reactive oxygen species. Physiol Rev 1994, 74:139-162.

150. Grotendorst GR, Hessinger DA: Enzymatic characterization of the major phospholipase A2 component of sea anemone (Aiptasia pallida) nematocyst venom. Toxicon 2000, 38:931-943.

151. Nevalainen TJ, Peuravuori HJ, Quinn RJ, Llewellyn LE, Benzie JAH, Fenner PJ, Winkel KD: Phospholipase A2 in Cnidaria. Comp Biochem Phys B 2004, 139:731-735.

152. Kaniewska P, Campbell PR, Fine M, Hoegh-Guldberg O: Phototropic growth in a reef flat acroporid branching coral species. J Exp Biol 2009, 212:662-667.

153. Levy O: Photobehavior of stony corals: responses to light spectra and intensity. J Exp Biol 2003, 206:4041-4049. 
154. Brady AK, Hilton JD, Vize PD: Coral spawn timing is a direct response to solar light cycles and is not an entrained circadian response. Coral Reefs 2009, 28:677-680.

155. Boch CA, Ananthasubramaniam B, Sweeney AM, Doyle FJ, Morse DE: Effects of light dynamics on coral spawning synchrony. Biol Bull 2011, 220:161-173.

156. Salih A, Larkum AWD, Cox G, Kühl M, Hoegh-Guldberg O: Fluorescent pigments in corals are photoprotective. Nature 2000, 408:850-853.

157. Roth MS, Latz Ml, Goericke R, Deheyn DD: Green fluorescent protein regulation in the coral Acropora yongei during photoacclimation. J Exp Biol 2010, 213:3644-3655.

158. Bay LK, Guérécheau A, Andreakis N, Ulstrup KE, Matz MV: Gene expression signatures of energetic acclimatisation in the reef building coral Acropora millepora. PLoS One 2013, 8:e61736.

159. DeSalvo MK, Sunagawa S, Voolstra CR, Medina M: Transcriptomic responses to heat stress and bleaching in the elkhorn coral Acropora palmata. Mar Ecol Prog Ser 2010, 402:97-113.

160. Tsang WH, McGaughey NJ, Wong YH, Wong J: Melatonin and 5-methoxytryptamine induced muscular contraction in sea anemones. J Exp Zool Part A 1997, 279:201-207.

161. Duffy DJ, Millane RC, Frank U: A heat shock protein and Wnt signaling crosstalk during axial patterning and stem cell proliferation. Dev Biol 2012, 362:271-281.

162. Meier S, Jensen PR, Adamczyk P, Bächinger HP, Holstein TW, Engel J, Özbek S Grzesiek S: Sequence-structure and structure-function analysis in cysteine-rich domains forming the ultrastable nematocyst wall. $J \mathrm{Mol} B \mathrm{Bio} /$ 2007, 368:718-728

163. Ann EJ, Kim HY, Seo MS, Mo JS, Kim MY, Yoon JH, Ahn JS, Park HS: Wnt5a controls Notch1 signaling through CaMKII-mediated degradation of the SMRT corepressor protein. J Biol Chem 2012, 287:36814-36829.

164. Itasaki N, Hoppler S: Crosstalk between Wnt and bone morphogenic protein signaling: a turbulent relationship. Dev Dyn 2009, 239:16-33.

165. Duffy DJ: Modulation of Wnt signaling: a route to speciation? Commun Integr Biol 2011, 4:59-61.

166. Carroll SB: Evo-Devo and an expanding evolutionary synthesis: a genetic theory of morphological evolution. Cell 2008, 134:25-36.

167. Abzhanov A, Protas M, Grant BR, Grant PR, Tabin CJ: Bmp4 and morphological variation of beaks in Darwin's finches. Science 2004 305:1462-1465.

168. Albertson RC, Streelman JT, Kocher TD, Yelick PC: Integration and evolution of the cichlid mandible: the molecular basis of alternate feeding strategies. Proc Natl Acad Sci U S A 2005, 102:16287-16292.

169. Clarke KR, Gorley RN: PRIMER V6: User Manual/Tutorial. Plymouth: PRIMER-E; 2006.

170. Anders S, Huber W: Differential expression analysis for sequence count data. Genome Biol 2010, 11:R106.

171. Anderson MJ: A new method for non parametric multivariate analysis of variance. Austral Ecology 2001, 26:32-46.

172. Pespeni MH, Barney BT, Palumbi SR: Differences in the regulation of growth and biomineralization genes revealed through long-term common-garden acclimation and experimental genomics in the purple sea urchin. Evolution 2013, 67:1901-1914.

173. Benjamini $Y$, Hochberg Y: Controlling the false discovery rate: a practical and powerful approach to multiple testing. J Roy Stat Soc B 1995, 57:289-300.

174. Gene-E. [http://www.broadinstitute.org/cancer/software/GENE-E/index.html]

175. Ashburner M, Ball CA, Blake JA, Botstein D, Butler H, Cherry JM, Davis AP, Dolinski K, Dwight SS, Eppig JT, Harris MA, Hill DP, Issel-Tarver L, Kasarskis A, Lewis S, Matese JC, Richardson JE, Ringwald M, Rubin GM, Sherlock G, Consortium GO: Gene ontology: tool for the unification of biology. Nat Genet 2000, 25:25-29.

176. Lee HK, Braynen W, Keshav K, Pavlidis P: ErmineJ: tool for functional analysis of gene expression data sets. BMC Bioinformatics 2005, 6:269.

doi:10.1186/1471-2164-15-1133

Cite this article as: Hemond et al:: The genetics of colony form and function in Caribbean Acropora corals. BMC Genomics 2014 15:1133.

\section{Submit your next manuscript to BioMed Central and take full advantage of:}

- Convenient online submission

- Thorough peer review

- No space constraints or color figure charges

- Immediate publication on acceptance

- Inclusion in PubMed, CAS, Scopus and Google Scholar

- Research which is freely available for redistribution

Submit your manuscript at www.biomedcentral.com/submit
C Biomed Central 